\title{
SUPPLEMENTARY MATERIAL: \\ Millisecond Pulsed Films Unify the Mechanisms of Cellulose Fragmentation
}

\author{
C. Krumm ${ }^{1}$, J. Pfaendtner ${ }^{2}$, P.J. Dauenhauer ${ }^{1, *}$ \\ ${ }^{1}$ University of Minnesota, Department of Chemical Engineering and Materials Science, 421 Washington Ave. SE, \\ Minneapolis, MN U.S.A. \\ ${ }^{2}$ University of Washington, Department of Chemical Engineering, 3781 Okanogan Lane NE, Seattle, WA U.S.A. \\ 98195 \\ *Corresponding Author. hauer@umn.edu
}

\section{Table of Contents}

S1. Design and validation of PHASR reactor

S1.1. PHASR Systems Assembly

S1.2. PHASR Validation

S2. PHASR System Detailed Design \& Methods $\quad 8$

S2.1. Sub-Assembly 1: PHASR Reactor

S2.2. Sub-Assembly 2: Heating Control.

S2.3. Sub-Assembly 3: Cooling Loop

S2.4. Sub-Assembly 4: Analytical Integration

S2.5. Units for Reaction Rates

S2.6. Characterization of quenched non-volatile samples

S3. Evaluation of transport limitations within reacting cellulose $\quad 24$

S3.2. Effect of Sample Characteristic Length. 25

S3.3. Elimination of Secondary Reactions. $\quad 27$

S4. $\alpha$-Cyclodextrin as a surrogate for cellulose $\quad 27$

S5. Transition from Zero to First Order Apparent Kinetics $\quad 28$

S6. Interpretation of Arrhenius Data $\quad 31$

S7. Cellulose Visualization $\quad 33$

S8. Tabulated PHASR Data $\quad 35$

Supplementary Information - References 


\section{S1. Design and validation of PHASR reactor}

The PHASR (Pulse Heated Analysis of Solid Reactions) reactor is an analytical tool designed to probe high-temperature millisecond-scale reactions on laboratory-scale. In this work, we present the detailed design of the PHASR reactor. PHASR design includes microreactor assembly, $1.0 \mathrm{kHz}$ control system integration, cooling system design, and analytical instrument integration. Heating and cooling reactor performance targets were evaluated with a global kinetic model, and measurement of transport limitations within reacting cellulose was used to ensure collection of isothermal kinetic data, as presented in the main paper. The PHASR microreactor is the first analytical tool for measuring high temperature millisecond-scale solid state reactions, providing capability to elucidate kinetics of previously immeasurable reactions, such as cellulose decomposition.
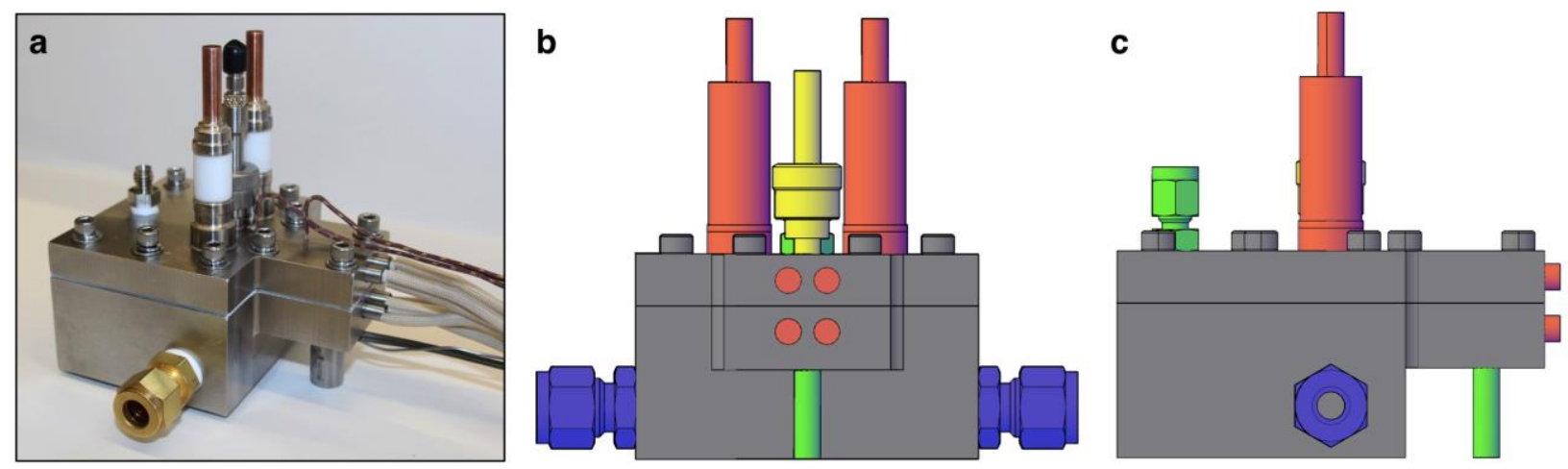

Figure S1. PHASR Reactor. The PHASR reactor is a laboratory-scale analytical device designed to rapidly heat and cool samples on a millisecond timescale via resistive heating and high-power cooling, thereby allowing for measurement of high temperature, sub-second reaction kinetics.

The PHASR reactor consists of two halves, a heating and a cooling section, which join together with a PTFE gasket to form the helium flow path, through which volatile products and rapidly transferred to the gas chromatograph. Figure S2 depicts the reactor halves, as well as a profile (panel b) and top-down (panel c) schematic of the sample, heating element, and electrical leads. 

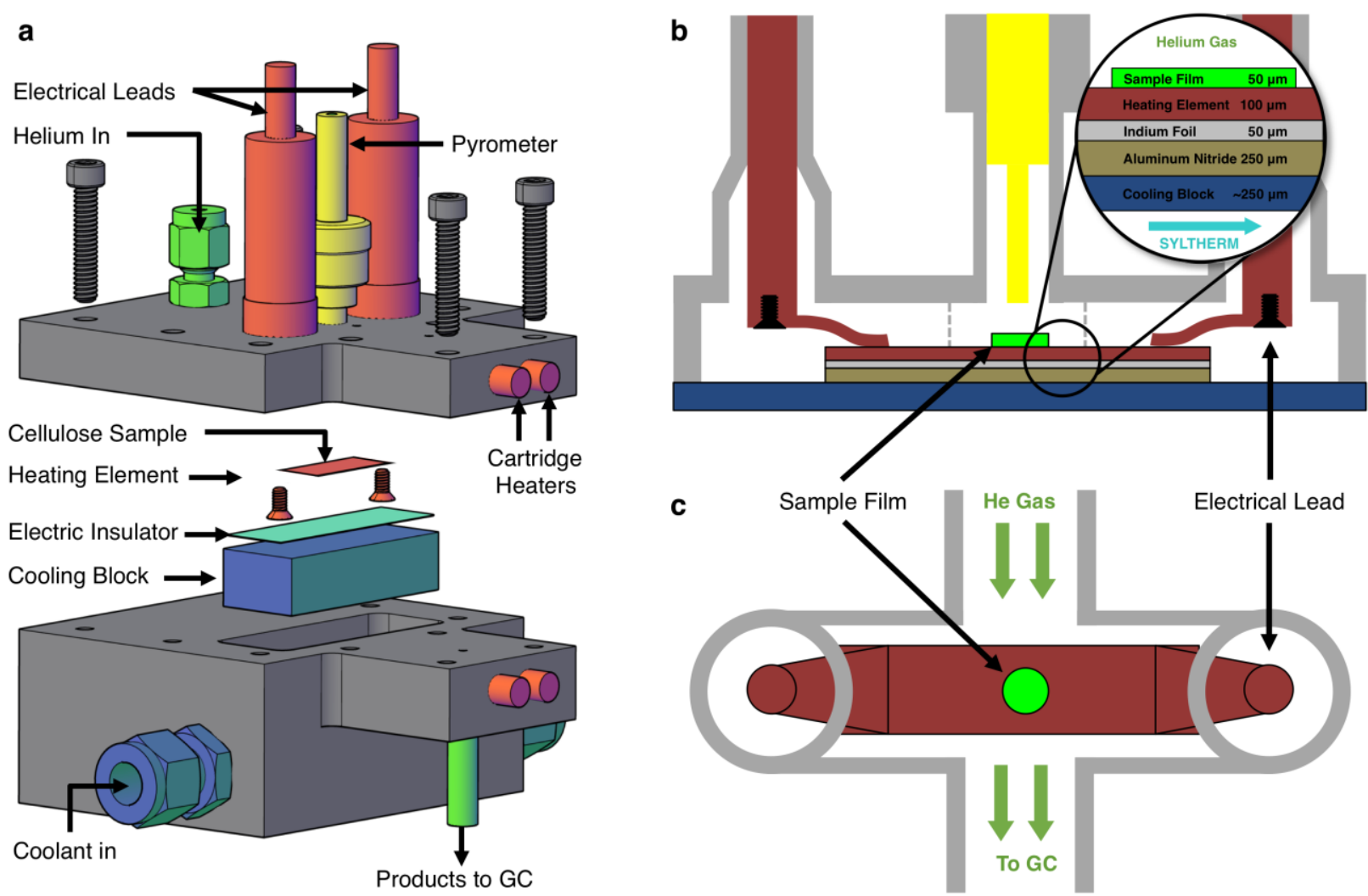

Figure S2. PHASR Microreactor Design A. An exploded diagram CAD model of the PHASR reactor shows an upper resistive heating section and a lower high velocity coolant section, both of which clamp together to form the helium sweep gas chamber. B. A side cross-sectional view of the PHASR reactor shows two electrical leads with copper brushes that clamp the heating element to maintain strong thermal contact between the sample film and the coolant (expanded view), while allowing for linear thermal expansion of the heating element. C. A top crosssectional view of the PHASR reactor shows the heating element with a thin-film sample loaded on the center and helium sweep gas constantly flowing across the center.

\section{S1.1. PHASR Systems Assembly}

The PHASR reactor is directly integrated with a gas chromatograph and mass spectrometer, heating control loop with optical pyrometer, and a cooling loop, as shown in Figure S3. 

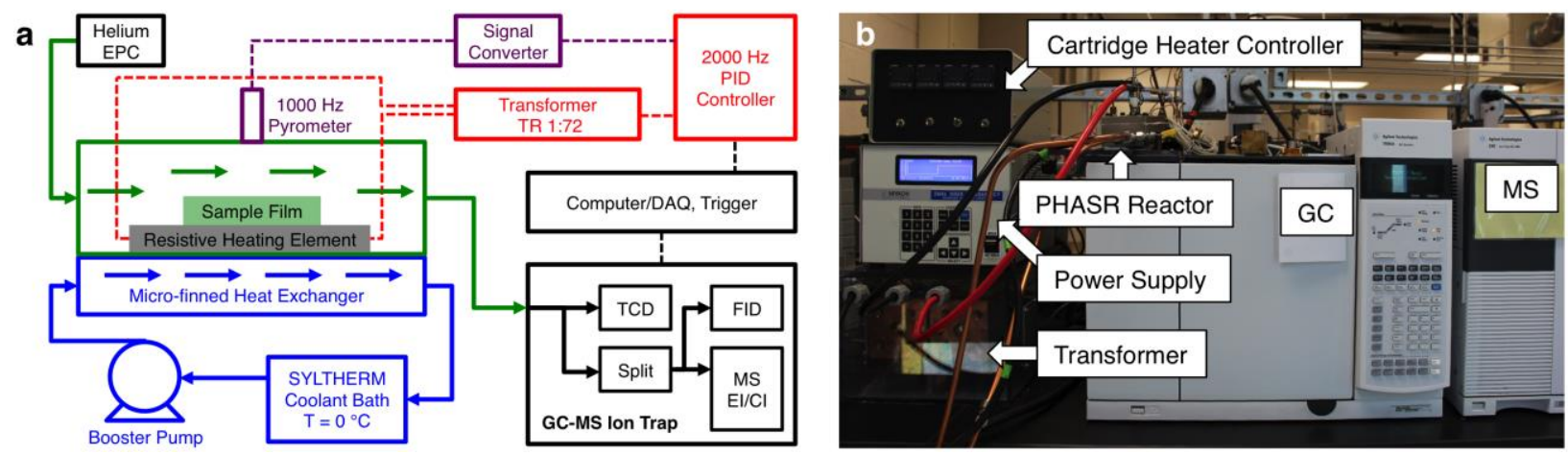

Figure S3. PHASR Systems Integration A. A schematic of the overall system shows the layout of the $1000 \mathrm{~Hz}$ PID heating controller, high velocity coolant loop, and direct integration with analytical equipment. B. A photo of the PHASR systems assembly, with the reactor directly integrated with the gas chromatograph inlet.

A major design requirement for the PHASR reactor is that it should be able to collect completely isothermal data - that is, the heating and cooling times are sufficiently short such that negligible reaction occurs during these times. Heating and cooling time targets were developed using a model that combined global kinetics from Shafizadeh and coworkers with a superimposed temperature profile containing a linear ramp heating profile, an isothermal hold at the set point temperature, and a linear ramp cooling profile ${ }^{11}$. By varying the heating and cooling times, a minimum heating a cooling rate was determined such that greater than 90 percent of the cellulose pyrolysis reaction occurs during the isothermal hold period, and less than 5 percent occurs during heating or cooling, respectively. The design parameters from this model were used as benchmarks for testing of the PHASR system.

During a PHASR reaction, a multitude of gas and volatile products are formed which must be quenched and rapidly swept to the GC inlet in order to prevent continued reaction or condensation. A three-dimensional COMSOL Multiphysics flow simulation of the helium flow path through the reactor was used to optimize the geometry of the PHASR reactor such that minimal axial dispersion occurs. The CAD helium flow path dimensions of the PHASR reactor were set as no-slip boundaries in the simulation, with a constant velocity prescribed at the reactor inlet, and a constant pressure at the outlet. The COMSOL laminar flow module was used to simulate helium flow, based on the small Reynold's number due to the narrow gas flow path.

To demonstrate the capability of the PHASR reactor to collect isothermal kinetic data, the experimental heating and cooling times were benchmarked with targets developed from the global kinetic model. 


\section{S1.2. PHASR Validation}

The PHASR reactor system was designed to probe the kinetics of high temperature reactions on a millisecond scale. By employing resistive heating with $1000 \mathrm{~Hz}$ feedback control in tandem with a high velocity heat transfer fluid, the PHASR microreactor heats and cools feedstocks in pulses on a millisecond timescale, thereby portioning the formation of products into segments for subsequent analysis via integrated GC-MS. Reactor geometry was optimized via three-dimensional fluid dynamics simulation to ensure rapid injection of gas and volatile products to the GC. Experimental validation demonstrates that the PHASR system is capable of heating from room temperature to $500{ }^{\circ} \mathrm{C}$ in fewer than $35 \mathrm{~ms}$ and, after holding the temperature for a desired time period, subsequent cooling in fewer than $150 \mathrm{~ms}$. When used to study cellulose pyrolysis, the PHASR system can effectively measure rates of formation of individual pyrolysis products in a reaction-dominant, isothermal system.

The flow path measured via COMSOL fluid dynamics simulation, shown in Figure S5C, shows highly linear helium streamlines through the PHASR reactor channel. Due to the narrow height of the channel, helium flow remains laminar (low Re), thereby ensuring negligible loss in GC peak resolution. With a gas-phase residence time across the heating element fewer than 10 milliseconds, pyrolysis products were rapidly quenched and injected onto the GC column. Rapid transfer of products from the PHASR to the gas chromatograph ensures negligible reaction of volatile products in the gas phase as outlined in section S3.3.

A major design consideration for the PHASR reactor was to ensure collection of isothermal data. As such, heating and cooling of the reactant sample must be sufficiently fast such that minimal reaction of reaction occurs during the heating or cooling phase. Targets for maximum allowable heating and cooling time were developed using a thermally resolved microkinetic model based on the lumped Broido-Shafizadeh kinetics ${ }^{11}$. The total heating and cooling time, as shown in the temperature profile in Figure S4D, was varied and the resulting quantity of volatile products formed during heating and cooling was calculated. A target heating time of 50 milliseconds and cooling time of 250 milliseconds yielded minimal formation of volatile products $(<5 \%)$ during each phase at $500{ }^{\circ} \mathrm{C}$, shown in Figure S4B. 

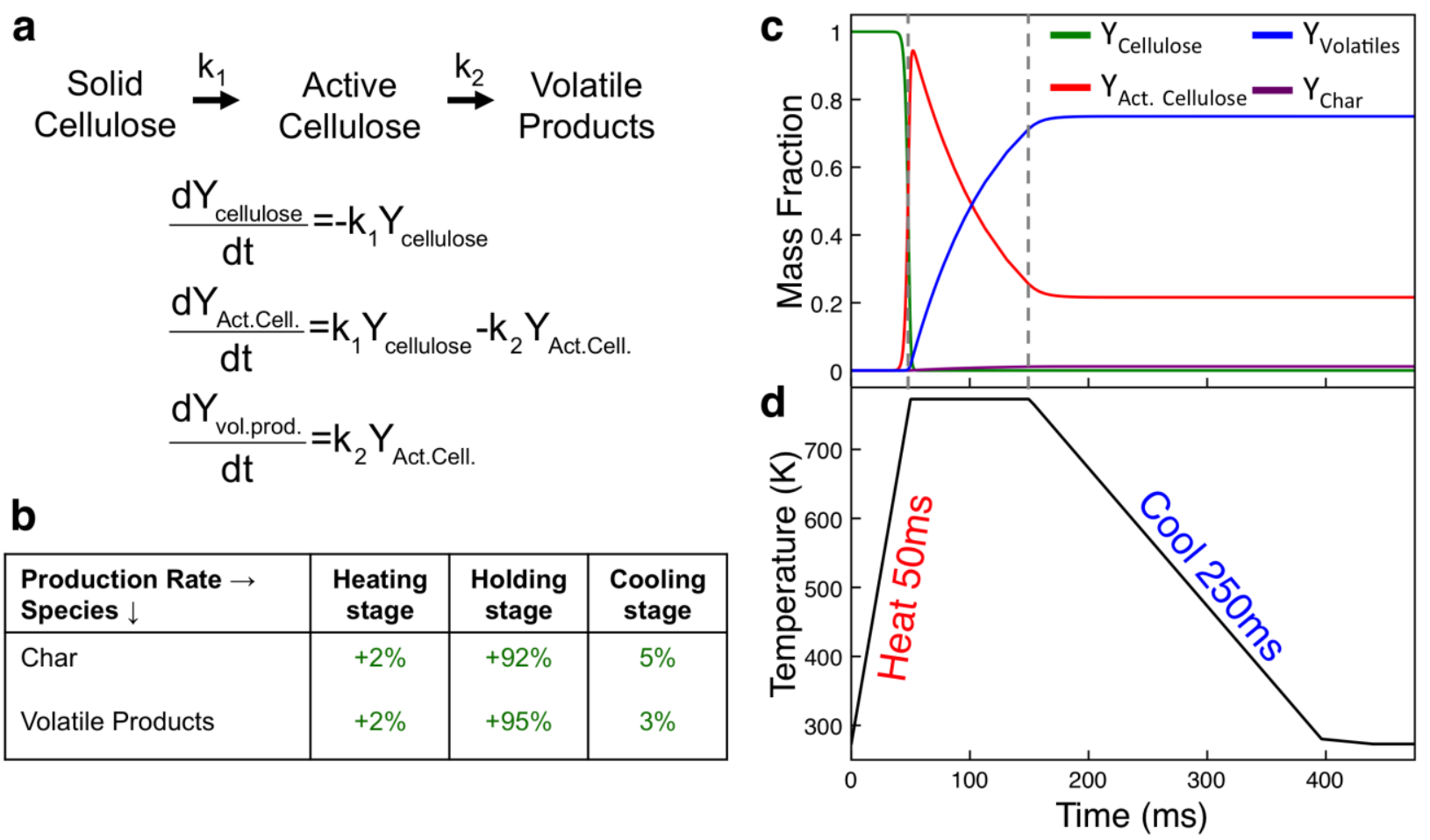

Figure S4. Lumped reaction kinetics (A) are combined with a superimposed temperature profile (D) to estimate the amount of volatile products formed for prescribed heating and cooling times. Minimum heating and cooling times of $50 \mathrm{~ms}$ and $250 \mathrm{~ms}$ at $500{ }^{\circ} \mathrm{C}$, respectively, indicates minimal volatiles formation $(<5 \%)$ during the heating and cooling stages, serving as targets for experimental validation of the PHASR reactor.

Primary experimental validation was conducted by measuring heating and cooling rates for comparison with the kinetic model benchmarks determined from the kinetic model. Shown in Figure S5A, the PHASR reactor was capable of heating to $500{ }^{\circ} \mathrm{C}$ in fewer than $35 \mathrm{~ms}$ (Goal: 50 $\mathrm{ms}$ ) and cooling in fewer than $150 \mathrm{~ms}$ (Goal: $250 \mathrm{~ms}$ ). A substantial improvement in cooling time was observed with an indium thermal interface foil used between the heating element and aluminum nitride layers as outlined in section S5B. Indium, which is known to melt around 250 ${ }^{\circ} \mathrm{C}$, forms a liquid layer between the aluminum nitride and heating element, allowing for rapid heat transfer across the composite material. The resulting cooling times from $550{ }^{\circ} \mathrm{C}$ are nearly twice as fast as those without indium. 

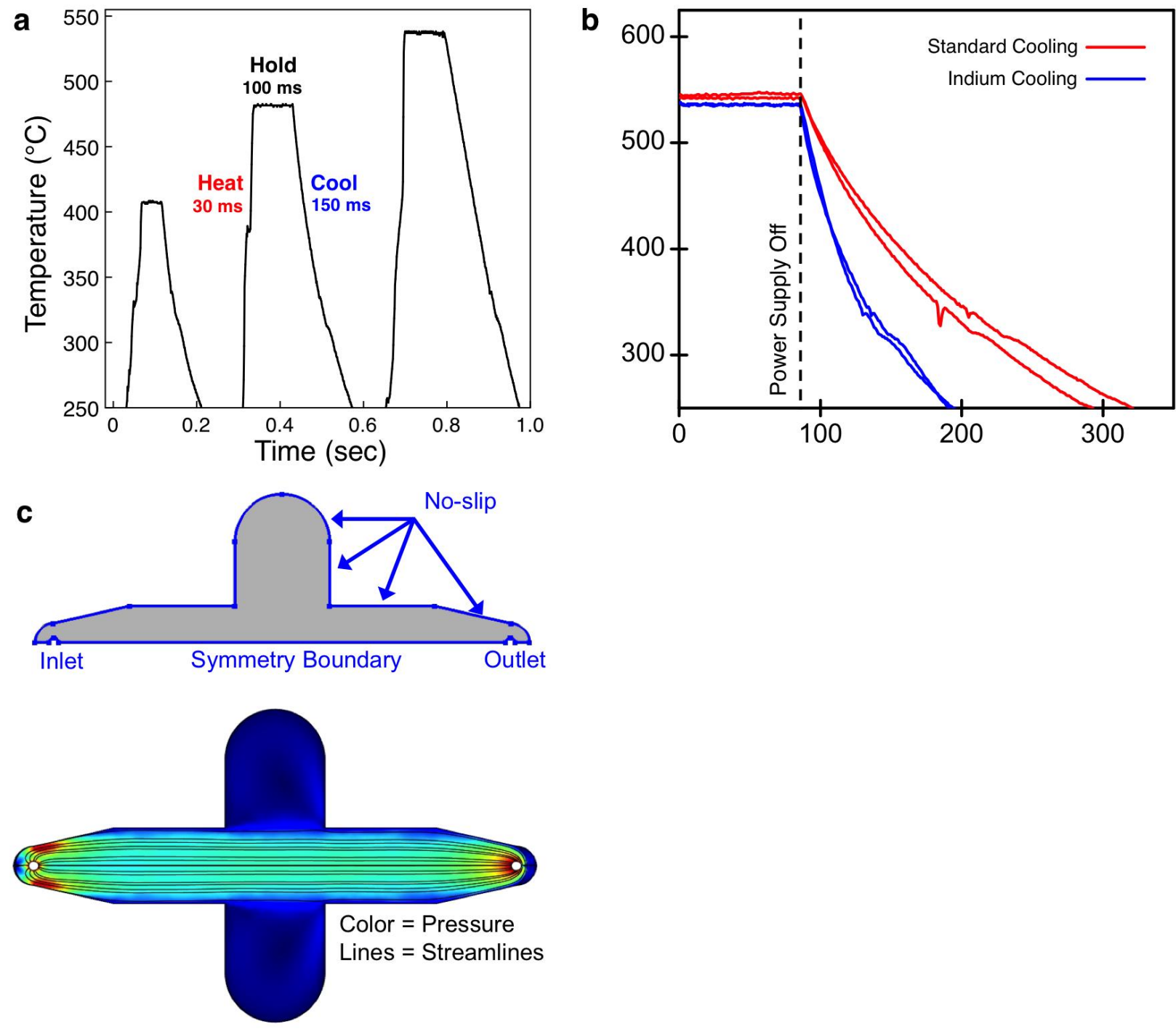

Figure S5. PHASR Results A. Temperature-time profiles generated using the PHASR reactor show capability to heat in less than $35 \mathrm{~ms}$ and cool in under $150 \mathrm{~ms}$. B. Comparison of characteristic cooling temperature profiles after power supply shutoff shows a factor of two decrease in cooling time from $550{ }^{\circ} \mathrm{C}$ to $250{ }^{\circ} \mathrm{C}$ with the indium layer present as a heat transfer medium. C. A COMSOL flow simulation with prescribed boundary conditions shows a highly linear helium flow path through the reactor, ensuring rapid transfer of gas and volatile products to the gas chromatograph.

The abstract of the manuscript establishes that the PHASR reactor is four orders of magnitude faster than conventional thermos-gravimetric analysis (TGA). TGA achieves temperature changes of $\sim 100{ }^{\circ} \mathrm{C} / \mathrm{min}$. PHASR achieves temperature changes of $\sim 500{ }^{\circ} \mathrm{C}$ in 30 milliseconds; this corresponds to a temperature change of about one million $\left(10^{6}\right){ }^{\circ} \mathrm{C} / \mathrm{min}$. The difference in these rates if $\operatorname{LOG}_{10}\left(10^{6} / 10^{2}\right)=4$. 


\section{S2. PHASR System Detailed Design \& Methods}

This section outlines the PHASR reactor design and includes assembly diagrams, manufacturing drawings, and detailed parts lists. The PHASR reactor consists of a microreactor in Figure S1 and several sub-assemblies including: (a) syltherm coolant cycle, (b) an optical pyrometer and signal converter, (c) a PID control system, and (d) a downstream analysis system.

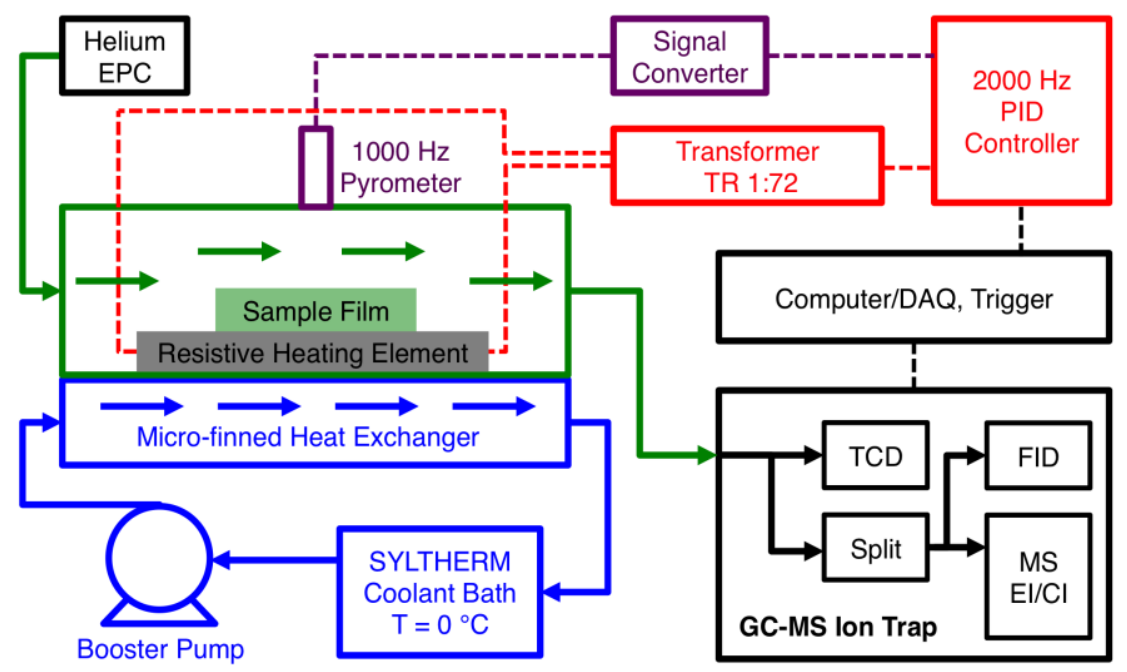

Figure S6. The PHASR system consists of five main sub-assemblies (color coded), each of which are outlined in subsequent sections.

The various sub-assemblies are color-coded in Figure S1 in the manner of Table S1.

Table S1. Overview of PHASR system sub-assemblies. Each sub-assembly is color coded to match Figure S1.

\begin{tabular}{lcll}
\hline Pulsed Film Kinetics Reactor Assembly & Page \# \\
\hline Sub-Assembly & Color & Description \\
1: PHASR Reactor & $\bullet$ & Machined Reactor Housing, integrates all sub-assemblies \\
2: Heating Control & $\bullet$ & PID feedback controlled power supply with transformer \\
3: Cooling Loop & $\bullet$ & High Velocity coolant loop for sample cooling \\
4: GC-MS & $\bullet$ & Analytical \\
\hline
\end{tabular}




\section{S2.1. Sub-Assembly 1: PHASR Reactor}

The PHASR reactor is a custom-machined housing which incorporates all other subassemblies. Millisecond heating via PID temperature feedback control is achieved through two electrical leads and a pyrometer incorporated into the top housing. A micro-finned heat exchanger with silicone coolant provides rapid cooling. Two fittings defining the reactor inlet and outlet allow for direct integration with analytical equipment. Finally, cartridge and nozzle heaters are used to uniformly heat the reactor housing to prevent product condensation. The following section outlines provides details for PHASR reactor design.

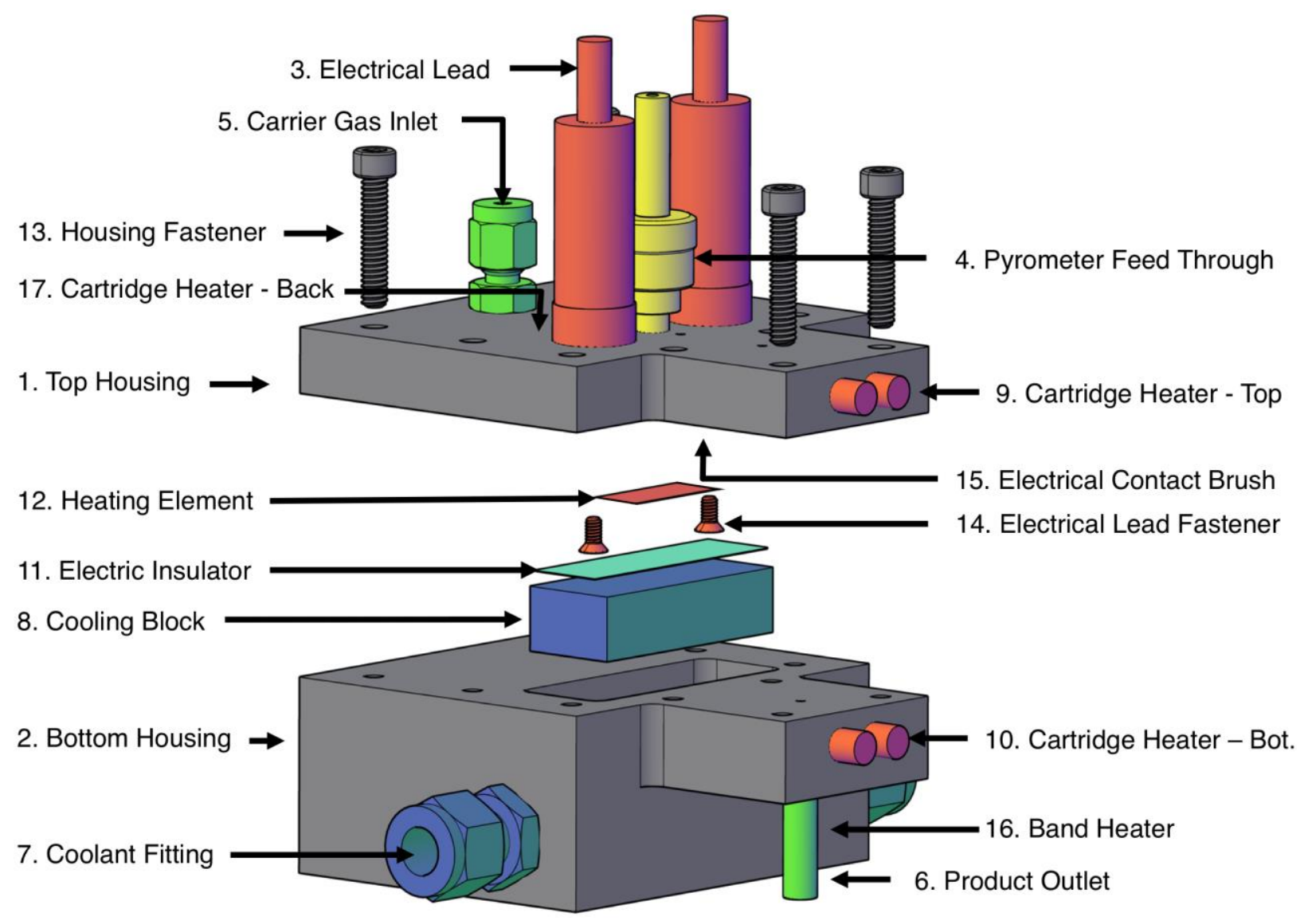

Figure S7. An exploded diagram shows all components of the PHASR reactor. Numbers are referenced in Table S2, which provides component details, as well as subsequent design sections.

Table S2 lists all of the components shown in Figure S7 and includes vendors and manufacturers for relevant parts. Notes and drawing references are provided for parts that are custom machined or modified before assembly. 
Table S2. Descriptions and product numbers for all components of Sub-Assembly 1: PHASR Reactor

\begin{tabular}{|c|c|c|c|c|}
\hline Part \# & Description & Vendor/Manufacturer & Part No. & Modification/Notes \\
\hline 1 & Top Housing & Custom & - & See Figure S9 \\
\hline 2 & Bottom Housing & Custom & - & See Figure S10 \\
\hline 3 & Electrical Feed Through & MPF Products Inc. & A0106-1-W & See Figure S12 \\
\hline 4 & Pyrometer Feed Through & Swagelok & SS-4-UT-A-4 & - \\
\hline 5 & Carrier Gas Inlet & Swagelok & SS-100-1-1 & - \\
\hline 6 & Product Outlet & Vici Valco & ZLTA41 & See Figure S11 \\
\hline 7 & Coolant Fitting & Swagelok & SS-600-1-6 & - \\
\hline 8 & Cooling Block & MicroCooling Concepts & SA-5A & \\
\hline 9 & Cartridge Heater - Top & Omega & HDC00034 & - \\
\hline 10 & Cartridge Heater - Bottom & Omega & HDC00034 & - \\
\hline 11 & Electric Insulator & Stellar Industries & ALN 2.0"X2.0"X.010" & $\begin{array}{c}\text { Cut to } 1 " \text { x } 0.35 " \\
\text { rectangles using glass } \\
\text { cutter }\end{array}$ \\
\hline 12 & Heating Element & McMaster-Carr & $655 \mathrm{~K} 84$ & See Figure S13 \\
\hline 13 & Housing Fastener & McMaster-Carr & $91251 \mathrm{~A} 246$ & - \\
\hline 14 & Electrical Lead Fastener & McMaster-Carr & 92451A077 & - \\
\hline 15 & Electrical Contact Brush & Custom & - & Figure S13 \\
\hline 16 & Band Heater & Nexthermal & Custom & See Part Details \\
\hline 17 & Cartridge Heater - Back & Omega & CIR-1014/120V & - \\
\hline
\end{tabular}

Figures S9 and S10 show detailed CAD drawings of the custom-machined PHASR reactor housings. Each reactor housing was machined from a solid block of 316 stainless steel. Careful attention was given to ensure a slide fit for all cartridge heaters as well as appropriate weld preps for the electrical feedthroughs, pyrometer feedthrough, and gas outlet fitting. An image of the final product is shown in Figure S8. Drawings of modified PHASR reactor components are shown in Figures S11 through S13.

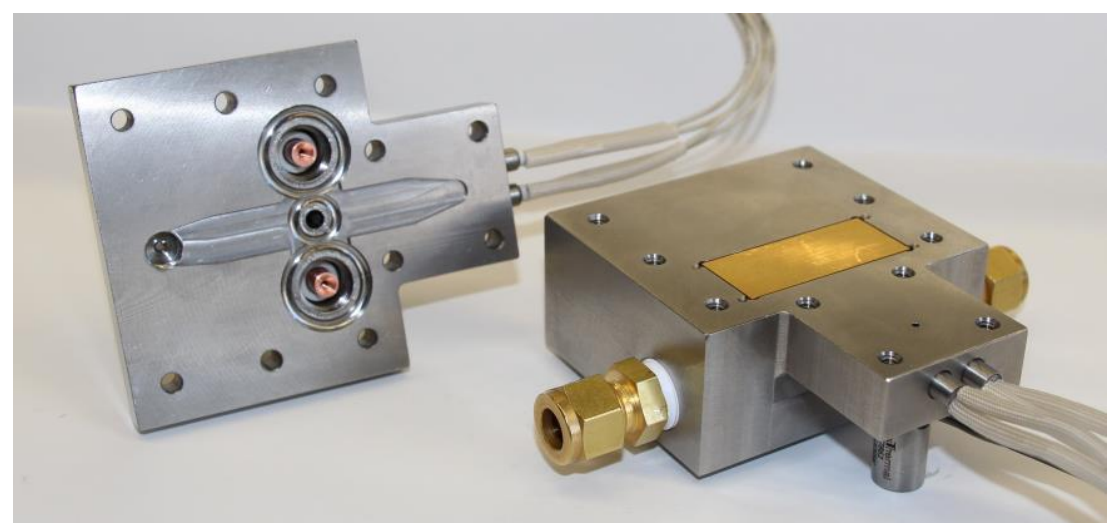

Figure S8. A photo of the assembled top and bottom section of the PHASR reactor housing. 

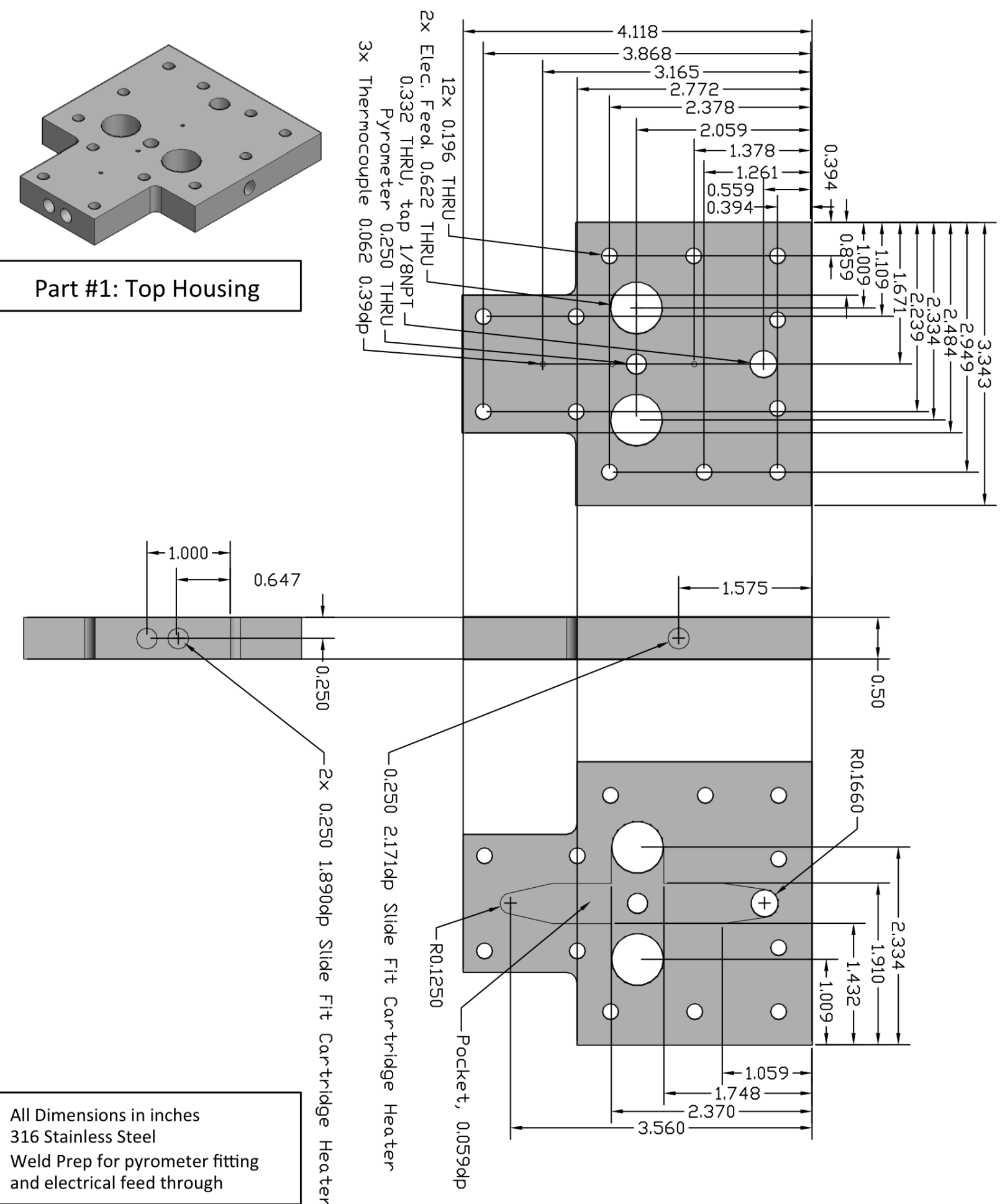

All Dimensions in inches 316 Stainless Steel

Weld Prep for pyrometer fitting and electrical feed through

Figure S9. CAD drawing of the PHASR reactor top housing, with all dimensions shown in inches. Custom machined from 316 stainless steel. The electrical and pyrometer feedthroughs were welded into the top housing. 


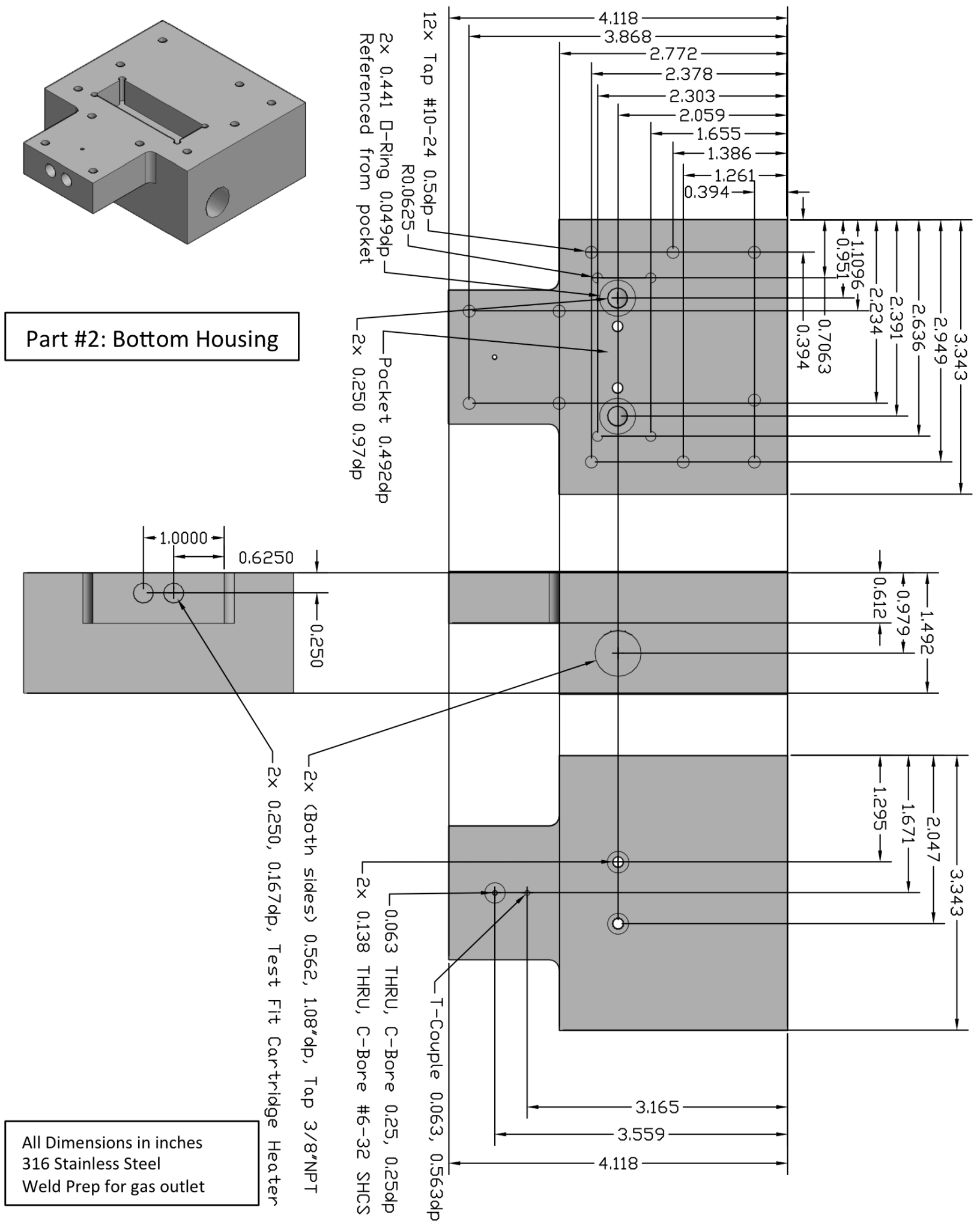

Figure S10. CAD drawing of the PHASR reactor bottom housing, with all dimensions shown in inches. Custom machined from 316 stainless steel. The gas outlet fitting was welded to the bottom housing. 
The gas outlet fitting (Part \#6) was shortened on a lathe according to the drawing shown in Figure S11. After modification, the fitting was welded into the bottom housing of the reactor such that the fitting sits flush with the bottom of the reactor housing.

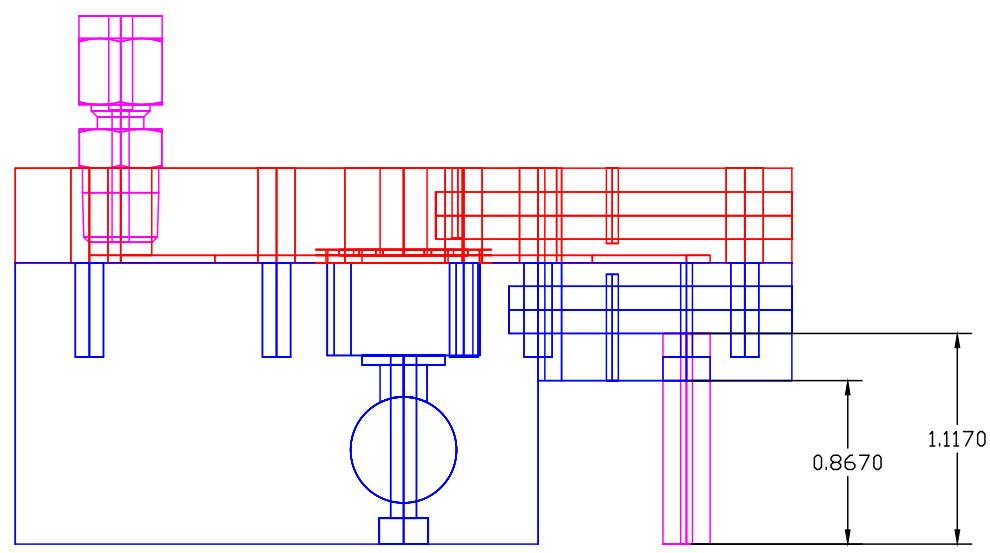

Figure S11. CAD drawing of the PHASR reactor with dimensions for modification of the VICI Valco fitting (Part \#6), which was shortened to the designated dimensions on a CNC lathe.

The electrical feed through (Part \#3) was modified on a lathe on the internal side of the reactor according to the drawing in Figure S12 such that the copper conductor (shown in yellow) extends only a small amount past the fitting housing. The copper conductor was then threaded and counter-bored to fit a \#2-56 flat head machine screw, which attaches the copper brush to the electrical feed through.

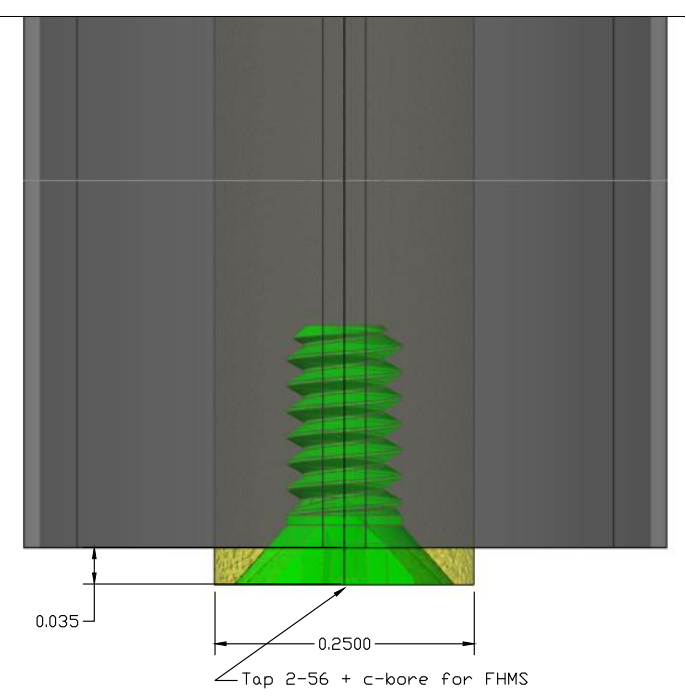

Figure S12. CAD drawing of the Electrical feed through. The copper conductor on the inside portion of the reactor was shortened to the shown dimensions, as well as tapped and counter-bored for a \#2-56 flat head machine screw (FHMS), which connects the feed through to the copper brush. 
In order to connect the electrical feed through to the heating element, a brush was manufactured out of 0.01 " thick copper according to the dimensions shown in Figure S13. The brush was screwed to the electrical feed through using a \#2-56 fastener (Part \#14). The brushes were bent such that, when the reactor is closed, the brushes press down on the heating element in order establish a strong electrical connection and press the heating element down to maintain good thermal contact with the aluminum nitride and cooling block to improve cooling times. The copper brushes were implemented in order to allow for heating element movement due to thermal expansion during rapid thermal heating and cooling. By this method, the heating element does not warp or bend upward during heating, which would significantly reduce heat removal during cooling.

Heating elements (Part \#12) were manufactured from 1010 carbon steel foil due to its low coefficient of thermal expansion. The one-inch wide foil was cut on a sheet metal table shear to the final dimension of 0.35 " 1 " (Figure S13). Due to the rapid heating and cooling, the heating elements quickly become brittle. Thus, each heating element is one-time use and hundreds of heating elements were manufactured at one time.
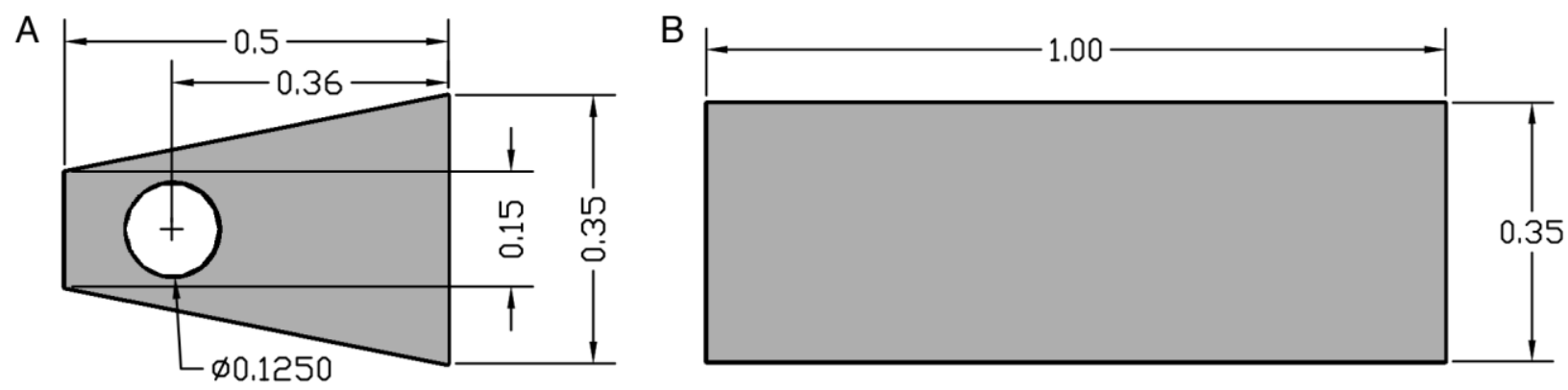

Figure S13. A. CAD drawing of the copper brush, which is bolted to the electrical feedthrough. The brush is bent such that it contacts the heating element when the reactor is closed. Dimensions are displayed in inches. B. Dimensions for cutting disposable heating elements (Part \#12) from 1010 steel foil using a sheet metal table shear.

As discussed in section S1.3, a substantial improvement in cooling was achieved by employing indium as a thermal interface material in between the heating element and aluminum nitride ceramic layers. Indium foil (Indium Corporation, Ribbonin-10101) was cut to the same dimensions as the heating element and gently pressed onto the aluminum nitride ceramic before placing the heating element on the composite layer. As with heating elements, indium foil pieces were used only once.

The PHASR reactor is heated via five cartridge heaters and one band heater, each of which is controlled via PID feedback control using thermocouple measurements. The heaters are 
divided into four heated zones: (1) top housing, back heater, (2) top housing heaters, (3) bottom housing heaters, and (4) transfer line heater. A custom control box, shown in Figure S14, was built to accept four thermocouple inputs and provide current for controlling the temperature of each heated zone. Figure S15 depicts a wiring diagram for all four heating circuits.

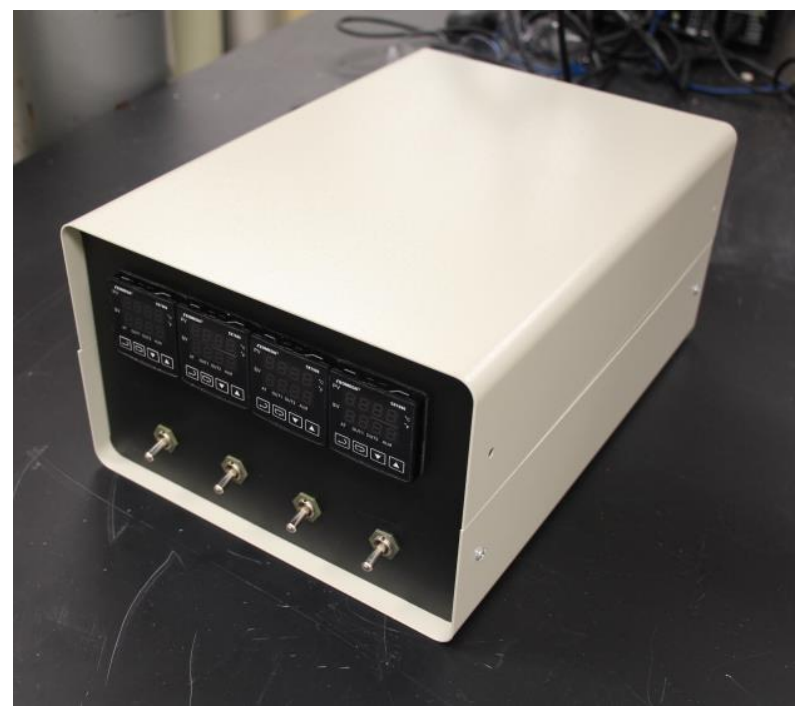

Figure S14. A custom-built cartridge heater controller capable of controlling all four heated zones on the PHASR reactor. 


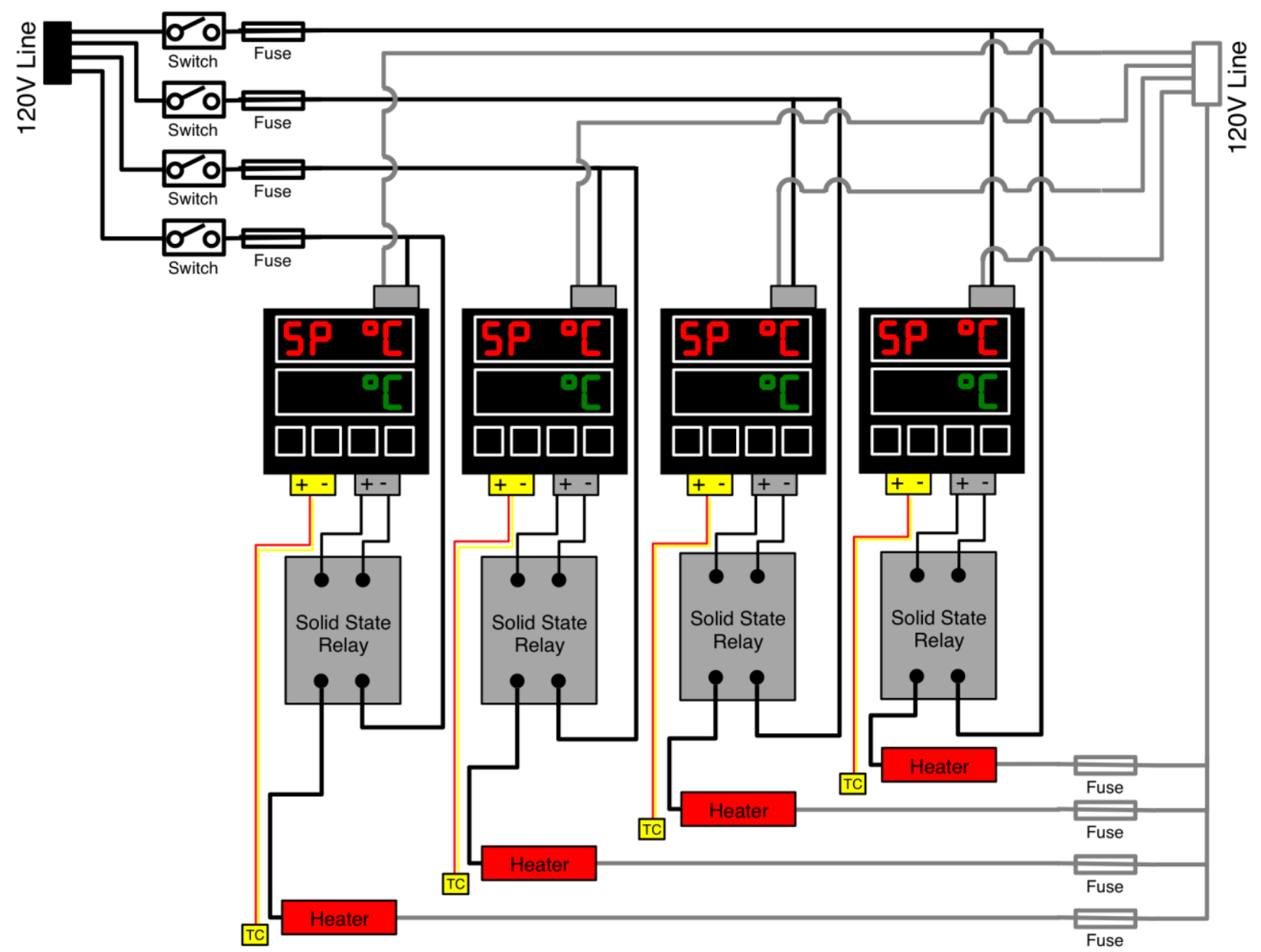

Figure S15. A wiring diagram of the custom-build heater controllers shows four independently controlled heating circuits using a PID feedback controller with k-type thermocouple in line with a solid state relay.

\section{S2.2. Sub-Assembly 2: Heating Control.}

Samples deposited on the steel heating elements used in the PHASR reactor are resistively heated to the set point temperature using a high frequency power supply and transformer with an optical pyrometer for feedback temperature control. An overall schematic of the heating control sub-assembly is shown in Figure S16. 


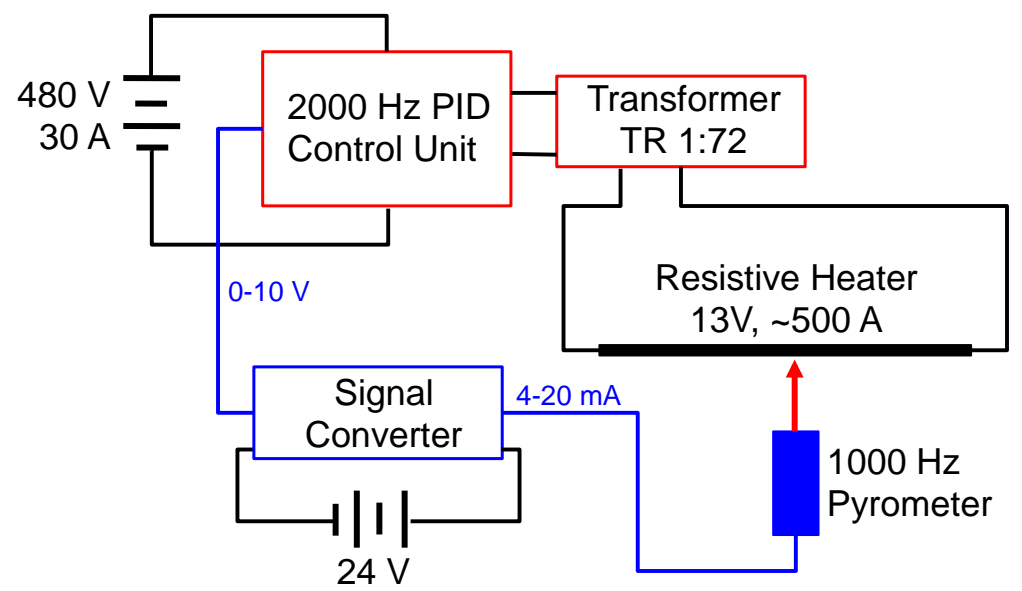

Figure S16. A schematic of the heater control sub-assembly shows the $2000 \mathrm{~Hz}$ power supply and controller, which sends the desired electrical power profile through the transformer and the heating element. Temperature is measured using an optical pyrometer for feedback with the power supply controller.

Table S3 lists all of the components shown in Figure S16 and includes vendors and manufacturers for relevant parts. Notes and drawing references are provided for parts that are custom machined or modified before assembly.

Table S3. Descriptions and product numbers for all components of Sub-Assembly 2: Heating Control

\begin{tabular}{cllcc}
\hline Part \# & Description & Vendor/Manufacturer & Part No. & Modification/Notes \\
\hline $\mathbf{1}$ & Power Supply & Miyachi-Unitek Corp. & HF-2 & - \\
$\mathbf{2}$ & Transformer & Miyachi-Unitek Corp. & IT1140-T & IGA-50-LO Plus \\
fiber optics \& light pipe \\
$\mathbf{4}$ & Optical Pyrometer & Lumasense/Impac & LP2-18.5mm & - \\
$\mathbf{5}$ & Signal Converter & Phoenix Contact & 2811284 & - \\
$\mathbf{6}$ & 24V Power Supply & Traco Power & TCL24-124C & St. length \\
$\mathbf{7}$ & Electrical Lead Cable & McMaster-Carr & 6948 K73 & Silver solder to electrical \\
& Bus Bar Interconnect & Tyco Electronics & & lead cable \\
$\mathbf{8}$ & Weld Ring Terminal & McMaster-Carr & T106K94 & Silver solder to electrical \\
& & & & lead cable \\
\hline
\end{tabular}

Heating of the PHASR reactor is controlled via a PID feedback loop using the optical pyrometer, signal converter, and power supply. The optical pyrometer interprets the infrared emission of the heating element and converts it into an analog signal that is proportional to temperature. A sapphire light pipe aimed at the heating element inside the PHASR reactor transfers the infrared signal via a fiber optic cable to the pyrometer sensor. A signal converter accepts the milliamp signal from the pyrometer and converts the signal to a 0-10 volt signal, 
which is fed back to the power supply controller. The power supply, which is conventionally used for resistive welding applications, accepts a voltage input, which is normally measured across welding heads to monitor weld quality. In this application, the power supply accepts a voltage proportional to the heating element temperature instead of a weld voltage. Figure S17 shows the integration of the optical pyrometer, fiber optic cable, and signal converter.

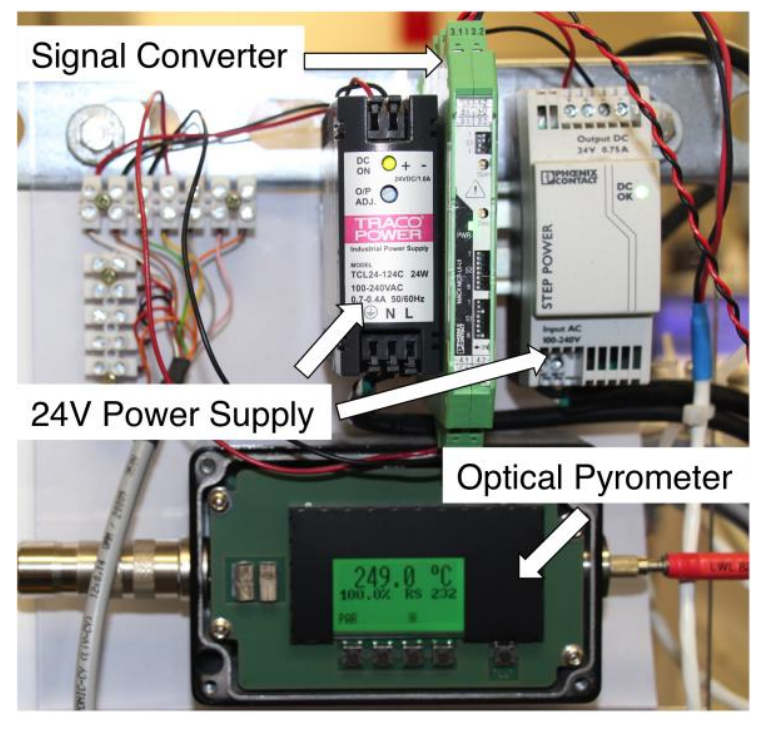

Figure S17. The optical pyrometer interprets the infrared emission spectrum of the heating element and converts the optical signal to an analog milliamp signal, which is converted to a voltage using the signal converter for feedback to the power supply.

A custom set of electrical leads was constructed, which connect the transformer to the PHASR reactor. Standard 2-gauge battery wire was terminated with a ring terminal and a 0.25 " bus bar connector, which provides quick connection with electrical feedthroughs. Figure S18 shows the cable assembly with the bus bar connector and ring terminal silver soldered to the wire.

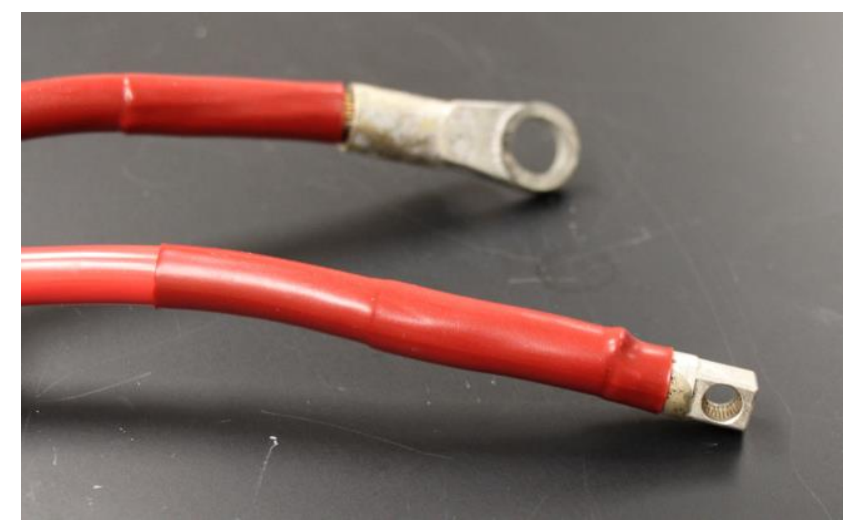

Figure S18. The custom-fabricated electrical leads connect the positive and negative terminals on the transformer to the PHASR reactor, allowing for quick connection and disconnection via bus-bar style connectors. 
The optical pyrometer was designed to measure the temperature in one-millisecond increments. As a result of the high sampling rate, the minimum readable temperature is $250{ }^{\circ} \mathrm{C}$. In order to operate the power supply in PID feedback mode, the temperature of the heating element must be above $250{ }^{\circ} \mathrm{C}$. This is accomplished by setting the power supply to a 'dual weld' mode, in which two consecutive programs can be carried out. The first program is set to provide a constant current of 500 amps through the heating element for a defined length of time to raise the temperature above $250{ }^{\circ} \mathrm{C}$. After this program is complete, a second program initiates PID feedback control, and the power supply controls at a constant, pre-selected voltage that corresponds to the desired temperature. Selecting the voltage that corresponds to a desired temperature is accomplished via linear interpolation of the pyrometer temperature measurement range $\left(250{ }^{\circ} \mathrm{C}-1350{ }^{\circ} \mathrm{C}\right)$ and the feedback signal to the power supply $(0-10 \mathrm{~V})$.

\section{S2.3. Sub-Assembly 3: Cooling Loop}

After the power supply has heated a sample to the desired temperature and maintained that temperature for a set period of time, the electric current to the heating element is stopped and the PHASR reactor relies on high-velocity coolant to rapidly cool the heating element. The cooling loop sub-assembly pumps a temperature-controlled silicon-based coolant (Dow, SYLTHER-800) through the cooling block in the PHASR reactor, thereby allowing for rapid quenching of the PHASR sample. The sub-assembly consists of a refrigerated reservoir to maintain coolant temperature, a booster pump to increase fluid velocity, and tubing and fittings for integration with the PHASR reactor. Table S4 lists the part numbers and vendors of components used in the cooling loop sub-assembly.

Table S4. Descriptions and product numbers for all components of Sub-Assembly 3: Cooling Loop

\begin{tabular}{cllcc}
\hline Part \# & Description & Vendor/Manufacturer & Part No. & Modification/Notes \\
\hline $\mathbf{1}$ & Refrigerated Bath & Thermo-Fisher & Isotemp 4100, R20 & - \\
$\mathbf{2}$ & Booster Pump & McMaster-Carr/Shur-Flo & $4272 \mathrm{~K} 21$ & - \\
$\mathbf{3}$ & 3/8" Copper Tubing & McMaster-Carr & $8955 \mathrm{~K} 121$ & - \\
$\mathbf{4}$ & Fitting, Pump in/out & Swagelok & SS-600-1-6 & - \\
$\mathbf{5}$ & Fitting, Refrigerated Bath & Thermo-Fisher & Cat. \# 13873884 & - \\
$\mathbf{6}$ & in/out & DOW Chemical & Syltherm-800 & - \\
\hline
\end{tabular}


Figure S19 depicts the cooling loop assembly, which is installed below the bench top. Copper coolant lines connect the refrigerated bath to the booster pump and the PHASR reactor. While the refrigerated bath circulates temperature-controlled coolant constantly, the booster pump is activated with a manual switch shortly before initiating a reaction.

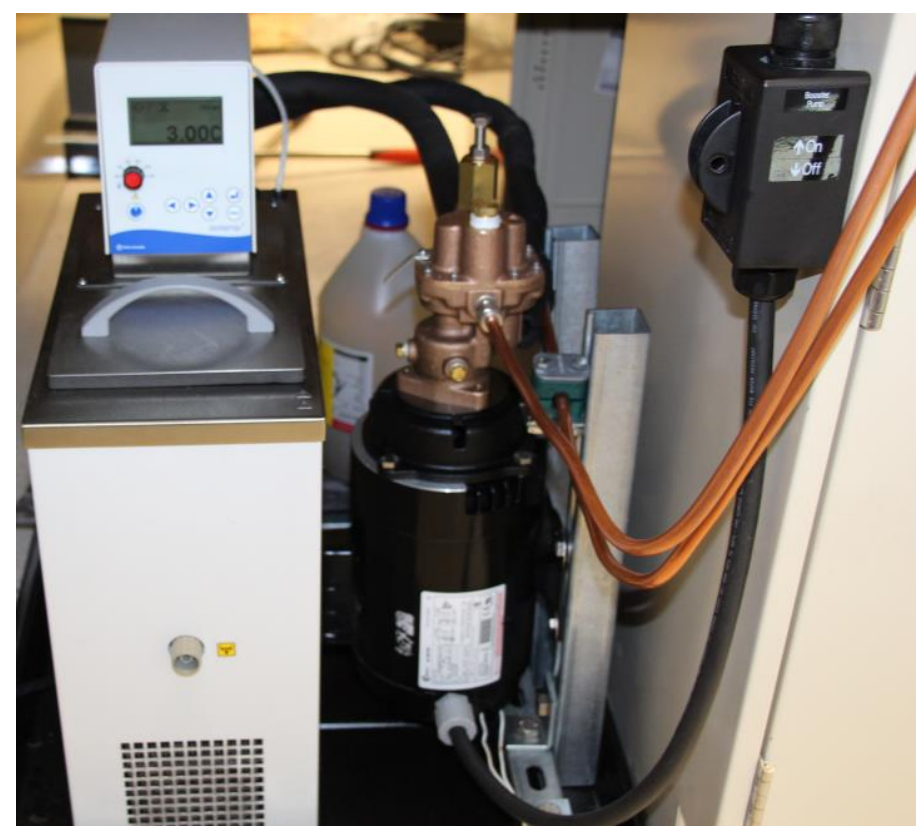

Figure S19. The cooling loop assembly consists of the refrigerated bath to maintain silicone coolant temperature at $3{ }^{\circ} \mathrm{C}$ and a booster pump to achieve a high linear coolant velocity across the cooling block in the PHASR reactor.

\section{S2.4. Sub-Assembly 4: Analytical Integration}

The PHASR reactor is integrated directly with a gas chromatograph (Agilent 7890A) for quantification and mass spectrometer (Agilent 220 Ion-Trap) for identification of gas and volatile components. Shown in Figure S20, the customized GC-MS setup incorporates a dual column setup with switching valve to separate gases and volatiles onto separate columns for tandem separation and detection. Gases are separated using a PLOT-Q column and quantified with a thermal conductivity detector (TCD). Volatiles are separated on the DB-5 column, after which a small portion is split to the mass spectrometer with electrical and chemical ionization capability for identification and the remainder is sent to a flame ionization detector (FID) for quantification. The electronic pressure controller (EPC) provides helium carrier gas at $200 \mathrm{sccm}$ through the PHASR reactor directly into the inlet of the gas chromatograph. A liquid nitrogen cryogenic focusing valve allows for $\mathrm{GC}$ oven temperatures as low as $-30{ }^{\circ} \mathrm{C}$ for separation of gases. 


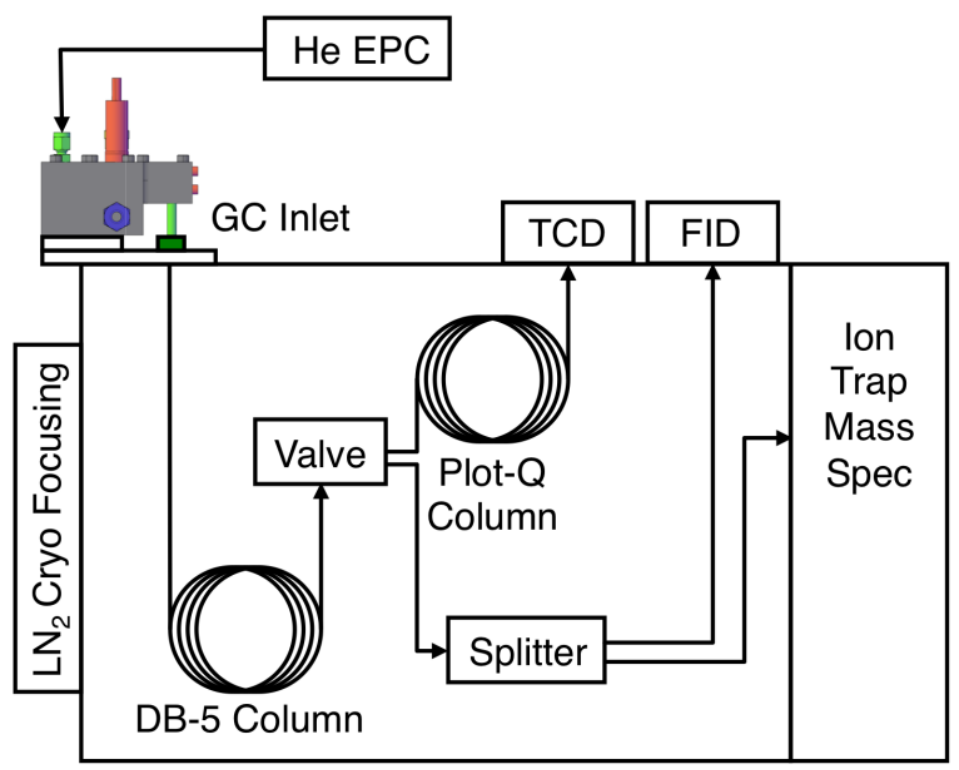

Figure S20. Integration of the PHASR reactor with a dual column gas chromatography setup with thermal conductivity detector, flame ionization detector, and EI/CI ion-trap mass spectrometer. The helium EPC provides carrier gas through the PHASR reactor for rapid transfer of products directly into the GC inlet.

For integration of the PHASR reactor with the inlet of the GC, a custom adapter was manufactured, shown in Figure S21. The adapter was made using a VICI Valco 1/16" nut and ferrule, 1/16" wide bore tubing, and a modified Agilent inlet nut and weldment, which was drilled to accommodate $1 / 16$ " tubing.

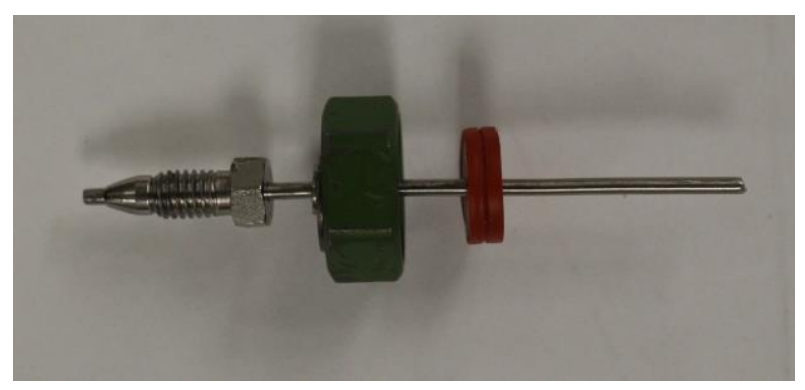

Figure S21. The custom adapter for integration of the PHASR reactor with the gas chromatograph consists of wide bore tubing, a VICI valco nut (left) for connection to the reactor, and a modified GC nut (green) and weldment for connection to the GC.

Gas and volatile products were rapidly transferred from the PHASR reactor to the GCMS via helium sweep gas, which is also used as a carrier gas for separation. The gas chromatograph method used for separation, quantification, and identification is outlined in Table S5. 
Table S5. Agilent GC-MS Method details for separation and identification of gas and volatile products from the PHASR reactor.

\begin{tabular}{lc}
\hline & Gas Chromatograph Method \\
\hline Inlet Temperature & $300{ }^{\circ} \mathrm{C}$ \\
Inlet He Pressure & $30 \mathrm{psi}$ for $2 \mathrm{~min}$, then $14 \mathrm{psi}$ \\
Inlet Split Ratio & $10: 1$ \\
Inlet Septum Purge & $3 \mathrm{~mL} / \mathrm{min}$ \\
Oven Ramp & $-30{ }^{\circ} \mathrm{C}$ to $260{ }^{\circ} \mathrm{C}$ in 70 min, hold $20 \mathrm{~min}$ \\
Valve Switch & All products to FID/MS after 2 min \\
Mass Spectrometer (EI mode) & Scan range m/Z 44 to 320 \\
\hline
\end{tabular}

All products were identified by matching retention times with purchased calibration standards, as well as identification via EI mass spectrometry. Table S6 lists retention times and primary ion fragments for all eight furan-based compounds. Calibration of compounds was performed by matching FID peak areas with known quantities of calibration standard for every GC analyte.

Table S6. GC retention times and major ions from EI mass spectrometry for all eight furan-based products presented in the main paper.

\begin{tabular}{|c|c|c|c|c|c|c|}
\hline \multirow[b]{2}{*}{ Compound } & \multirow[b]{2}{*}{ Structure } & \multirow{2}{*}{$\begin{array}{c}\text { Retention } \\
\text { Time }\end{array}$} & \multirow{2}{*}{$\begin{array}{l}\text { Molar } \\
\text { Mass }\end{array}$} & \multicolumn{3}{|c|}{ Major Ion Fragments } \\
\hline & & & & Ion & $\begin{array}{c}\text { Relative } \\
\text { Height }\end{array}$ & $\begin{array}{c}\text { Fragment } \\
\text { Lost }\end{array}$ \\
\hline Furan & & 10.73 & 68 & 82 & 999 & - \\
\hline \multirow{3}{*}{ 2-methylfuran } & & \multirow{3}{*}{18.3} & \multirow{3}{*}{82} & 68 & 999 & - \\
\hline & & & & 53 & 905 & $-\mathrm{CHO}$ \\
\hline & & & & 81 & 854 & $-\mathrm{H}$ \\
\hline \multirow{3}{*}{ 2,5-dimethylfuran } & & \multirow{3}{*}{27.53} & \multirow{3}{*}{96} & 96 & 999 & - \\
\hline & & & & 95 & 987 & $-\mathrm{H}$ \\
\hline & & & & 53 & 863 & $-\mathrm{C} 2 \mathrm{H} 3 \mathrm{O}$ \\
\hline \multirow{2}{*}{ furfural } & & \multirow{2}{*}{37.51} & \multirow{2}{*}{96} & 96 & 693 & - \\
\hline & & & & 95 & 999 & $-\mathrm{H}$ \\
\hline \multirow{3}{*}{ 2-furanmethanol } & & \multirow{3}{*}{39.68} & \multirow{3}{*}{98} & 98 & 999 & - \\
\hline & & & & 97 & 619 & $-\mathrm{H}$ \\
\hline & & & & 81 & 53 & $-\mathrm{OH}$ \\
\hline
\end{tabular}




\begin{tabular}{|c|c|c|c|c|c|c|}
\hline & & & & 69 & 614 & $-\mathrm{CHO}$ \\
\hline & & & & 53 & 831 & -45 \\
\hline \multirow{2}{*}{ 2(5H)Furanone } & & \multirow{2}{*}{44.75} & \multirow{2}{*}{84} & 84 & 286 & - \\
\hline & & & & 55 & 999 & $-\mathrm{CHO}$ \\
\hline \multirow{4}{*}{ 5-methylfurfural } & & \multirow{4}{*}{48.7} & \multirow{4}{*}{110} & 110 & 739 & - \\
\hline & & & & 109 & 747 & $-\mathrm{H}$ \\
\hline & & & & 53 & 999 & -57 \\
\hline & & & & 51 & 503 & -59 \\
\hline \multirow{3}{*}{$\begin{array}{c}\text { 5-hydroxymethyl } \\
\text { furfural }\end{array}$} & & \multirow{3}{*}{65.43} & \multirow{3}{*}{126} & 126 & 279 & - \\
\hline & & & & 97 & 999 & $-\mathrm{CHO}$ \\
\hline & & & & 69 & 803 & -57 \\
\hline
\end{tabular}

\section{S2.5. Units for Reaction Rates}

Reaction rates shown in the main paper are defined as:

$$
r_{\mathrm{i}}=\frac{(\text { mol spec } i)}{\left(\frac{M_{\text {reactant }}{ }^{D} \text { Preactant }}{M W_{\text {reactant }}}\right) *\left(\Delta \mathrm{t}_{H}\right)}
$$

where the amount of species $\mathrm{i}$ is detected by flame ionization detection, $\Delta \mathrm{t}_{\mathrm{H}}$ is the reaction hold time in seconds, $\mathrm{M}_{\text {reactant }}$ is the mass of reactant used in each sample, $\mathrm{MW}_{\text {reactant }}$ is the molecular weight of the reactant feedstock, and $\mathrm{DP}_{\text {reactant }}$ is the degree of polymerization of the reactant feedstock (i.e. $\mathrm{DP}=6$ for cellohexaose and $\mathrm{DP}=2$ for cellobiose). For cellulose, the molecular weight was calculated using an average degree of polymerization of 133, as measured by Mettler et $\mathrm{al}^{35}$. Scaled reaction rates shown in grey in Figure $3 \mathrm{D}$ and $3 \mathrm{~F}$ are normalized to the number of moles of chain ends present in the reactant material, which is equivalent to the number of moles of reactant:

$$
r_{\mathrm{i}}=\frac{(\text { mol spec } i)}{\left(\frac{M_{\text {reactant }}}{M W_{\text {reactant }}}\right) *\left(\Delta \mathrm{t}_{H}\right)}
$$

\section{S2.6. Characterization of quenched non-volatile samples}

Analysis of partially-reacted, quenched samples was performed using liquid chromatography. $\alpha$ cyclodextrin was used as a surrogate for cellulose is not quantifiable via liquid chromatography. Figure S22 depicts a sample LC chromatogram with a distinct $\alpha$-cyclodextrin peak at 48 minutes. 


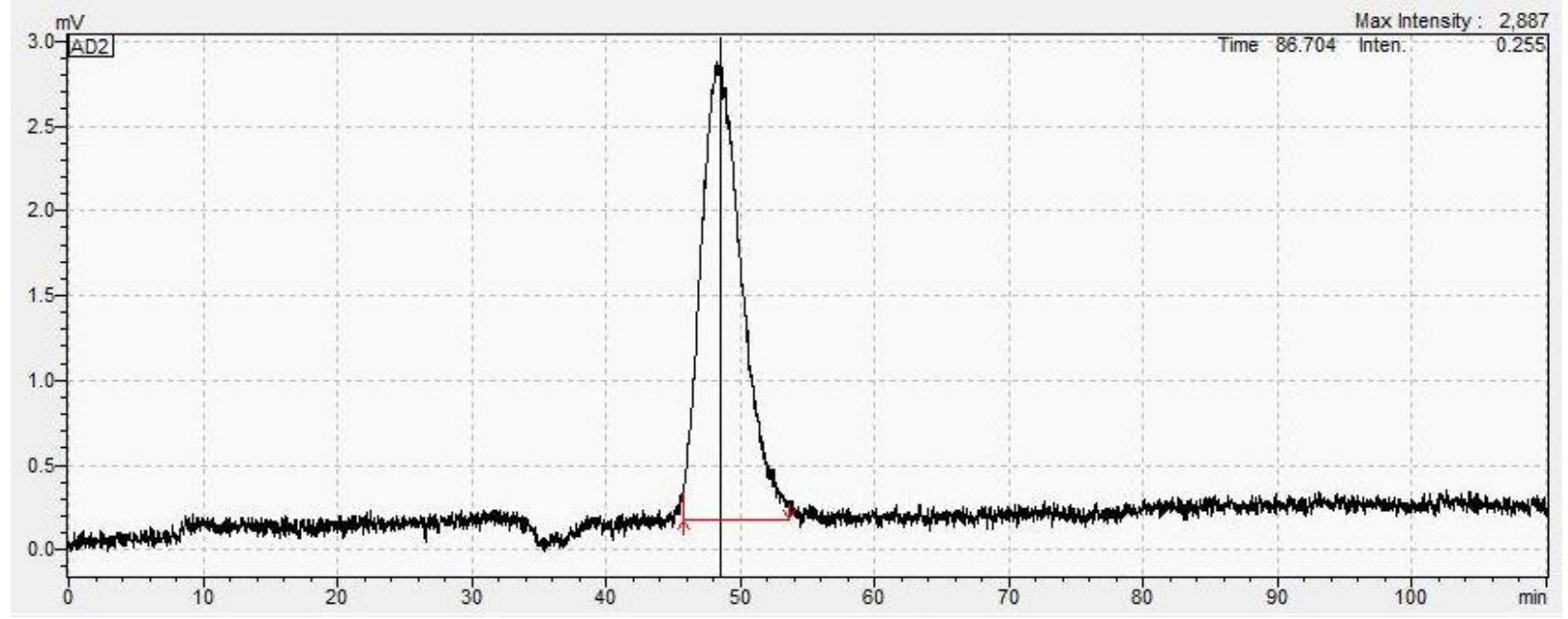

Figure S22. LC chromatogram from light scattering detection of an unreacted film of $\alpha$-cyclodextrin that was dissolved in water and filtered.

\section{S3. Evaluation of transport limitations within reacting cellulose}

In Figure 3B of the main paper, we varied the characteristic length/size of solid cellulose films $(20 \mu \mathrm{m}<\mathrm{L}<100 \mu \mathrm{m})$ under pyrolysis conditions and identified the transition between transport-limited and reaction-limited kinetics for cellulose pyrolysis at $400{ }^{\circ} \mathrm{C}$. In the supplementary information, we provide addition detail on the experiments conducted to obtain this data as well as additional data to identify the onset of transport limitations at $550{ }^{\circ} \mathrm{C}$.

Cellulose films of tunable thickness were individually prepared and characterized, and the resulting reaction rates for variable film samples were evaluated to identify the transition from reaction-limited to transport-limited conditions. Differential kinetics at high temperature allowed for clear identification of the kinetic transition to transport-limited conditions, visible as a distinct reduction in product formation rates with increasing cellulose film thickness.

As shown in Figure S23B, three-dimensional representation of all cellulose film thicknesses indicates that the deposition method produced an even application of cellulose material. Moreover, the film thickness was tunable between 20 and $200 \mu \mathrm{m}$, as shown in Figure S23A. 

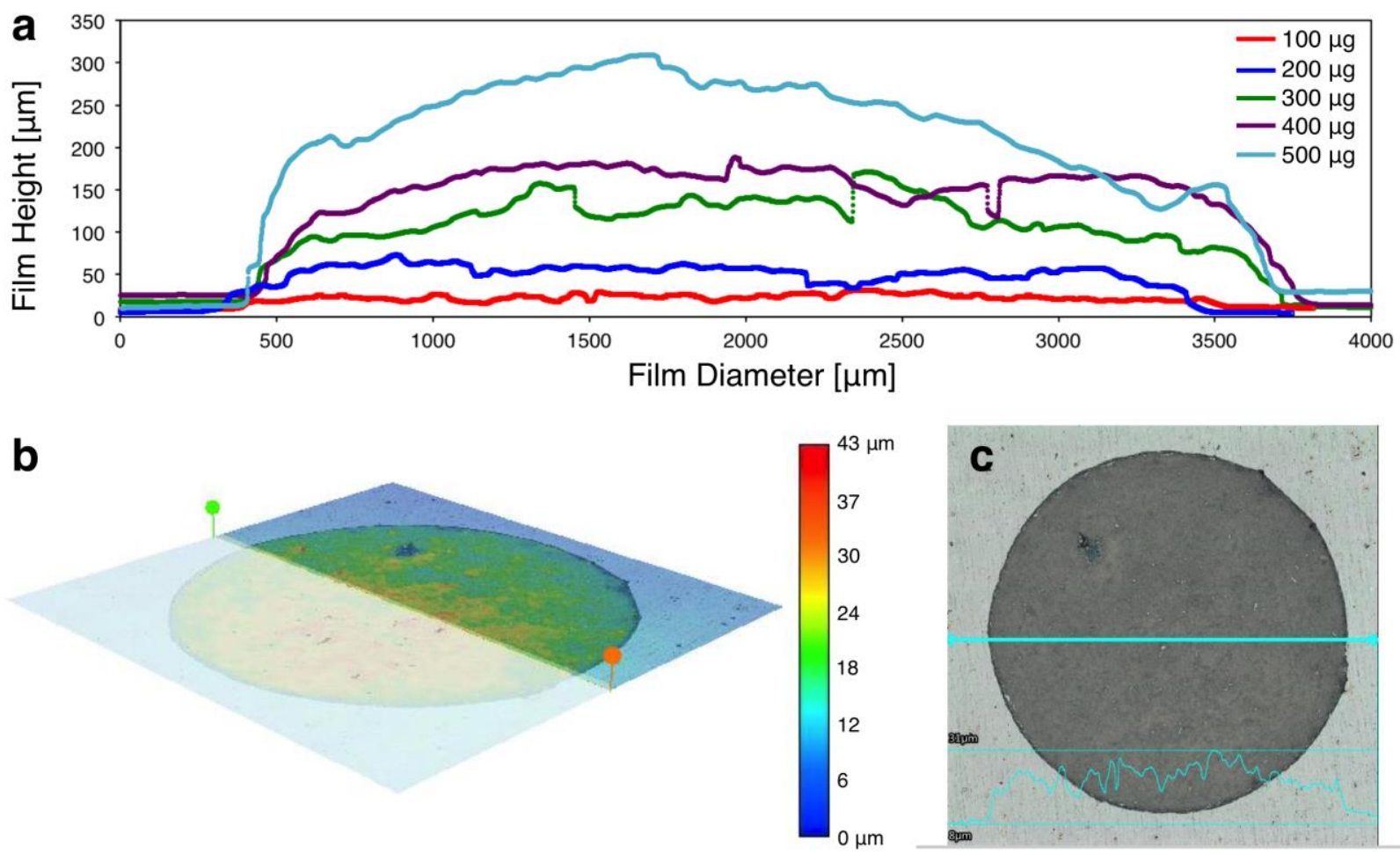

Figure S23. A. Optical profilometry of unreacted cellulose films of equal diameter but increasing mas loading (100$500 \mu \mathrm{g}$ ) shows uniform films with tunable thickness varying from 20 to 200 microns. B,C. Three dimensional optical profilometry of films shows uniform, circular films approximately $3 \mathrm{~mm}$ in diameter.

\section{S3.2. Effect of Sample Characteristic Length.}

Volatile compounds from reaction of cellulose films at $500{ }^{\circ} \mathrm{C}$ and $550{ }^{\circ} \mathrm{C}$ were quantified at short reaction times (conversion $<20 \%$ ) to measure initial formation rates, $\mathrm{r}_{\mathrm{i}}[=]$ mol $_{\text {product, }{ }^{*}}$ mol $_{\text {cellulose-monomer }}{ }^{-1} * \mathrm{~s}^{-1}$.

Evaluation of the reaction (formation) rates of four organic species reveals a distinct transition with variable sample thickness. As shown in 3B of the main paper, the formation rate remains constant at $500{ }^{\circ} \mathrm{C}$ for 2,3-butanedione, furfural, 2-furanmethanol, and 1,2cyclopentanedione when the sample thickness is below about $70 \mu \mathrm{m}$. The complete data set with absolute kinetics is depicted in Figure S24. For cellulose samples thicker than $70 \mu \mathrm{m}$, the formation rate of these four product compounds steadily decreased as the sample thickness increased indicating transport limitations. The same analysis conducted at $550{ }^{\circ} \mathrm{C}$, shown in Figure S25, indicates an onset of transport limitations above 20 microns. 

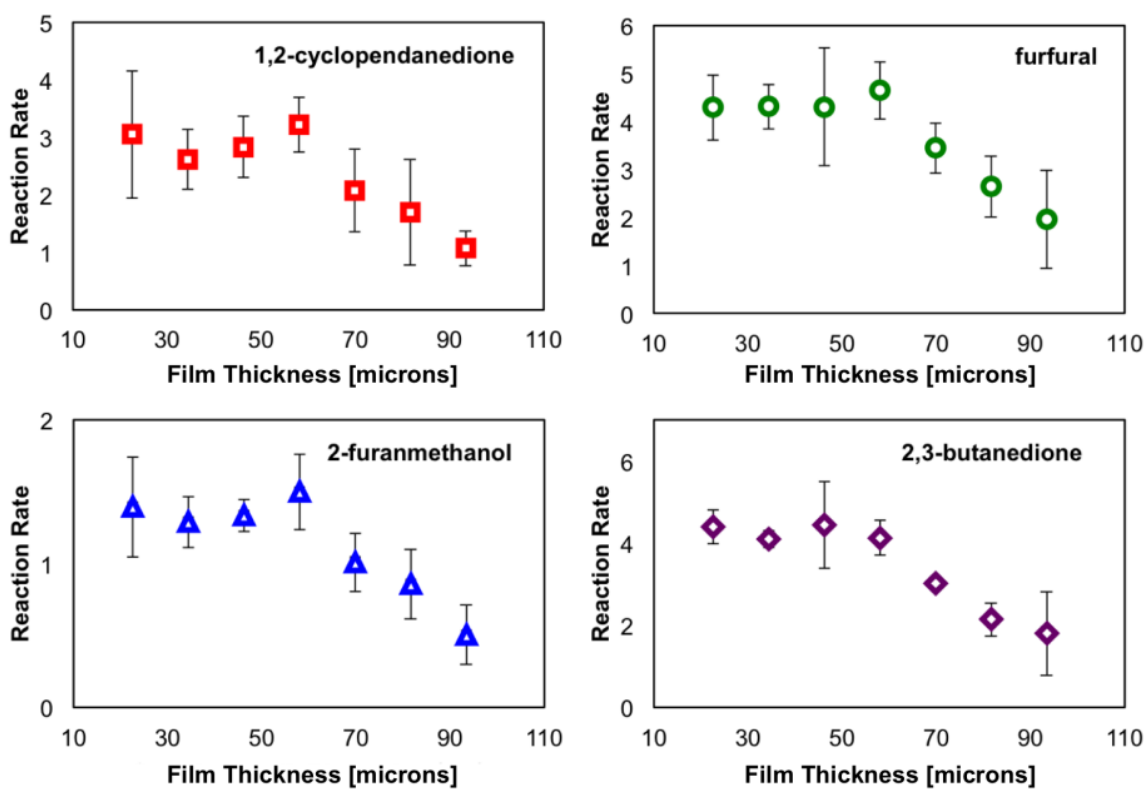

Figure S24. Initial kinetics of product formation for four different cellulose pyrolysis product species measured at $\underline{\mathbf{5 0 0}}{ }^{\circ} \mathbf{C}$ for films of increasing thickness, as shown in Figure 3B of the main paper, quantify the onset of transport limitations within reacting cellulose. Apparent reaction rates (moles product per mole cellulose monomer per second) stay constant with increasing cellulose film thickness up to 60 microns, after which the reaction rate decreases, indicating the onset of heat or mass transport limitations within reacting cellulose.
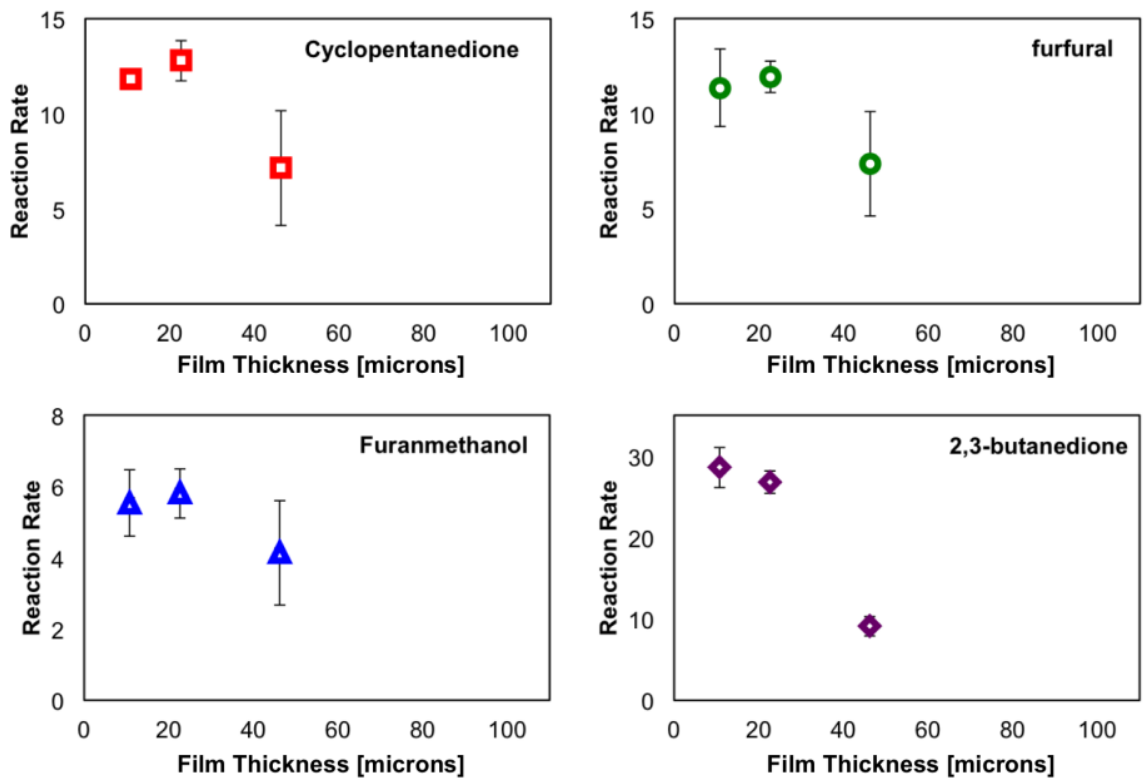

Figure S25. Initial kinetics of product formation for four different cellulose pyrolysis product species measured at $\underline{\mathbf{5 5 0}}{ }^{\circ} \mathbf{C}$ for films of increasing thickness. Apparent reaction rates (moles product per mole cellulose monomer per second) stay constant with increasing cellulose film thickness up to 20 microns, after which the reaction rate decreases, indicating the onset of heat or mass transport limitations within reacting cellulose.

Identification of the length scales relevant to transport limitations within reacting cellulose was relevant to ensure collection of isothermal, reaction-limited data as presented in the 
main paper. Across all temperatures, film thicknesses of reacting cellulose were chosen to be within the isothermal, reaction-limited regime as indicated in each experimental data set.

\section{S3.3. Elimination of Secondary Reactions.}

The thermal decomposition of cellulose undergoes primary reactions to produce volatile compounds in the considered experiments of this manuscript. Volatile products produced by either intra-chain or chain-end scission do not undergo additional secondary reactions prior to detection via gas chromatograph - mass spectrometry. To support this statement, two types of secondary reactions must be considered: (a) 'secondary reactions' have been identified as the additional reactions of volatile products within molten cellulose prior to evaporation ${ }^{7}$, and (b) other definitions of 'secondary reactions' have identified the reactions of the gas phase. The first category of melt-phase secondary reactions were eliminated by the use of thin films of cellulose. As depicted in the previous section in Figures S24 and S25, sufficiently thin films allow for volatile products to diffuse to the melt-gas interface and evaporate at least an order of magnitude faster than the rate of melt phase reactions; thus, the reaction rate becomes constant as all volatile products are produced only via the primary reaction pathways. The secondary reactions in the gas phase were eliminated by use of rapid sweep and quench gas as described in the reactor design. The PHASR microreactor was designed to eliminate mixing, and gas flows and chamber design enabled laminar flow with low residence time $(<10 \mathrm{~ms})$. For the gas flow rates selected and the PHASR microreactor volume, the residence time of the flowing helium used to entrain volatile products across the heating element was fewer than 10 milliseconds.

\section{S4. $\alpha$-Cyclodextrin as a surrogate for cellulose}

The kinetics of cellulose polymer conversion presented in Figure 4 of the main paper are measured using $\alpha$-cyclodextrin as a surrogate, because small changes in cellulose upon reaction cannot be readily quantified via common analytical techniques such as liquid chromatography. Methods such as gel permeation chromatography (size exclusion chromatography) only provide a determination of polymer size distribution.

In contrast, cyclodextrins comprised of six $(\alpha)$, seven $(\beta)$, or eight $(\gamma)$ monomers are

readily quantified by liquid chromatography. Moreover, $\alpha$-cyclodextrin has been previously shown to exhibit identical product distributions compared with cellulose ${ }^{35}$. The cyclic six- 
membered glucan structure effectively mimics the high degree of polymerization of cellulose with negligible presence of chain ends. Additionally, previous work has shown that there exists no quantifiable difference between alpha-linkages as observed in $\alpha$-cyclodextrin and betalinkages in cellulose ${ }^{27}$.

In this work, comparison of the initial product formation rates of furan-class compounds between $\alpha$-cyclodextrin and cellulose is shown in the plot of Figure S26. Cellulose and $\alpha$ cyclodextrin exhibit identical product formation kinetics, indicating that cyclodextrin is a good surrogate for cellulose kinetics $\left(400-500{ }^{\circ} \mathrm{C}\right)$ which is in both the chain-end and intra-chain kinetic regimes (i.e. above and below $\mathrm{T}_{\mathrm{RM}}$ ).

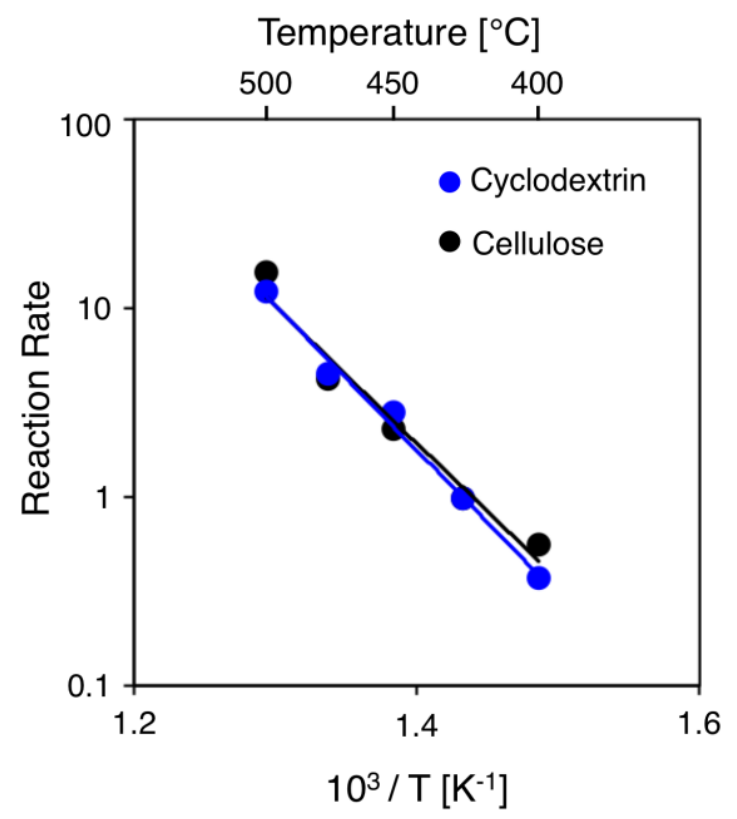

Figure S26. Arrhenius plot of initial kinetics of furfural production from cellulose (black) and $\alpha$-cyclodextrin (blue) shows that the two polymers exhibit identical kinetics

\section{S5. Transition from Zero to First Order Apparent Kinetics}

A major conclusion in the main paper is the transition from zero-order apparent kinetics at low temperature to first-order apparent kinetics at high temperature. The interpretation described in the main manuscript was a shift at low temperature of chain-end chemistry to midchain glycosidic bonds being rapidly cleaved above the reactive melting point $\left(\mathrm{T}_{\mathrm{RM}}=467^{\circ} \mathrm{C}\right)$. Evidence supporting this shift in mechanism is shown in Figure 3D and 3F, where the reaction rate scales directly with the number of chain ends below $\mathrm{T}_{\mathrm{RM}}$, and with the number of monomers above $\mathrm{T}_{\mathrm{RM}}$. 


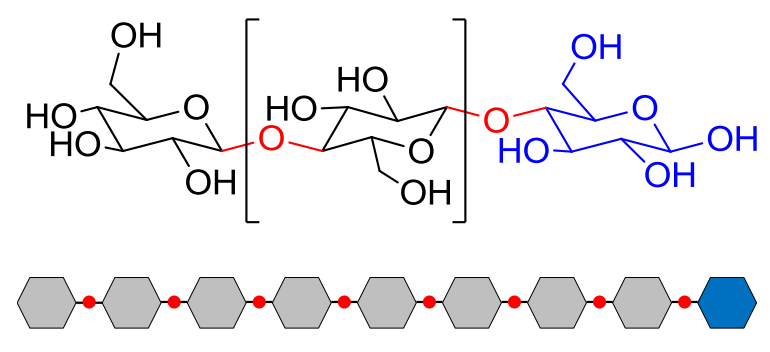

\section{Cellulose Monomer}

\section{Cellulose Reducing End}

Glycosidic Bond

Figure S27. Definition of cellulose chain components.

An interpretation of the apparent kinetics of Figure 3 is proposed in the main paper to consist of chain end versus intra-chain glycosidic cleavage. As shown in Figure S27, the cellulose chain is comprised of internal monomers, a 'reducing end' identified in blue, and a non-reducing end (grey). Each monomer is connected with an ether linkage between C1 and C4 of connecting monomers with $\beta$ stereochemistry; it is thus called $\beta$ - $(1,4)$-glycosidic bond.

As depicted in Figure S28, the mechanisms of chain-end cleavage versus intra-chain cleavage result in distinct differences in apparent kinetics of cellulose conversion and product formation. If the chain end(s) are the active site for polymer chemistry, then the depiction of extent of reaction in Figure S28A indicates that the chain ends (highlighted in blue) will remain constant with extent of reaction; conversion of a chain end results in a monomeric product as well as a new chain end. Thus, as depicted in Figure S28B, the concentration of chain ends remains constant until the reaction is completed. The cellulose decomposition rate by this mechanism will then be proportional to the concentration of chain ends; the end result is that the cellulose conversion rate is constant, yielding the apparent zero-order dependence on reactant concentration. This behavior was observed below $\mathrm{T}_{\mathrm{RM}}$ in Fig. 3E. 

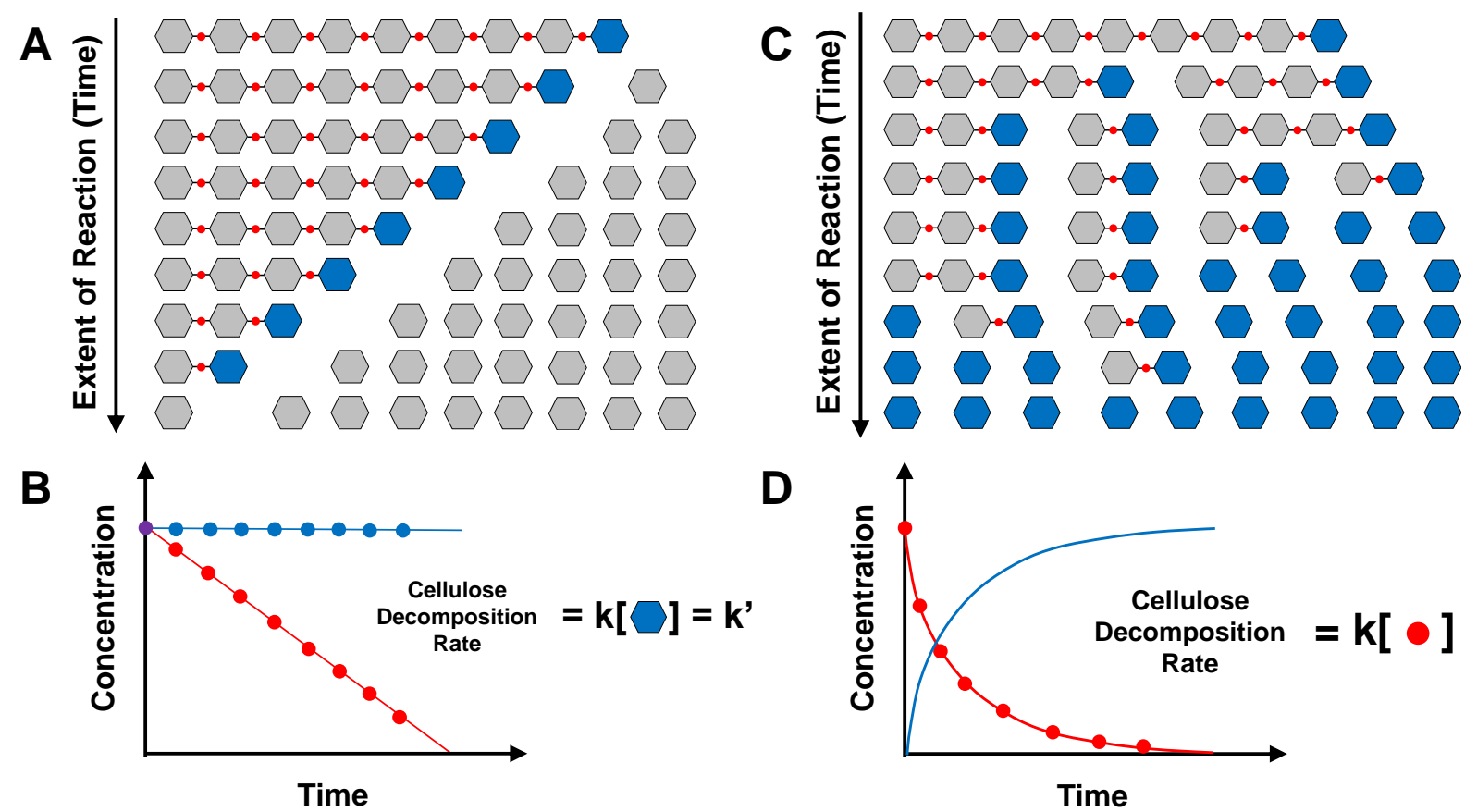

Figure S28. Kinetics of chain-end (A/B) and intra-chain (C/D) cellulose cleavage.

In contrast, the mechanism of intra-chain scission via glycosidic cleavage depicted in Fig. S28C will deplete the number of glycosidic bonds (red in Fig. S28C) with increasing extent of reaction. Thus, if the reaction rate of cellulose decomposition is proportional to the concentration of glycosidic bonds, then the rate of cellulose decomposition will decrease with time as depicted in Fig. S28D. The end result is that cellulose conversion exhibits apparent first order rate dependence.

The formation of volatile furan products was shown to exhibit first order apparent kinetics in Fig. 3 above $\mathrm{T}_{\mathrm{RM}}$ at $\mathrm{T}=500{ }^{\circ} \mathrm{C}$. However, the rate of cellulose conversion and product formation are decoupled at high temperature where intermediate products form rapidly.

$$
T>467^{\circ} \mathrm{C}, \quad \text { Cellulose } \stackrel{\text { Fast }}{\longrightarrow} \text { Intermediate Liquid } \stackrel{\text { Slow }}{\longrightarrow} \text { Volatile Products }
$$

For this reason, additional experiments were conducted to also examine the kinetics of cellulose conversion above $\mathrm{T}_{\mathrm{RM}}$. As shown in Figure S29, cellulose conversion kinetics at $500{ }^{\circ} \mathrm{C}$ were examined using the cyclodextrin surrogate; $\alpha$-cyclodextrin consumption was measured with time. Polymer conversion was observed to exhibit first-order apparent kinetics, in which the rate of conversion (i.e. the slope of the line) decreases with reaction time. This result supports the shift in mechanism from end-chain chemistry below $\mathrm{T}_{\mathrm{RM}}$ to rapid intra-chain scission at temperatures exceeding $\mathrm{T}_{\mathrm{RM}}$. 


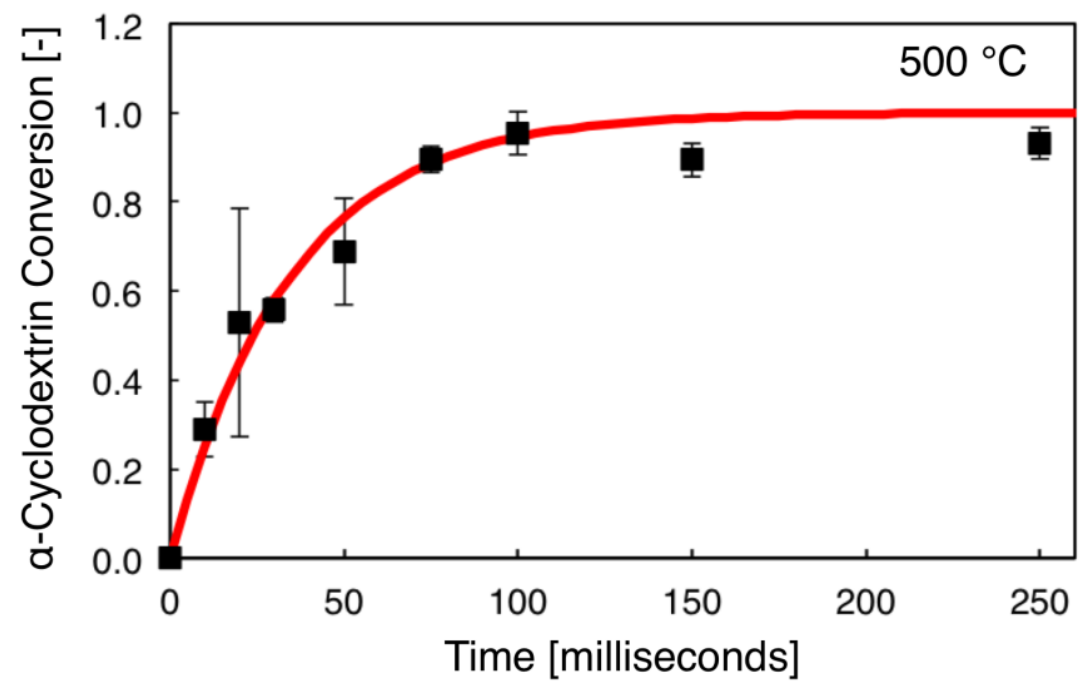

Figure S29. Conversion of $\alpha$-cyclodextrin with time at $500{ }^{\circ} \mathrm{C}$ (black) with a first-order fit line (red) shows that polymer conversion above the reactive melting point $\left(\mathrm{T}_{\mathrm{RM}}=467{ }^{\circ} \mathrm{C}\right)$ exhibits first order behavior, supporting the shift in mechanism from end-chain chemistry below $\mathrm{T}_{\mathrm{RM}}$ to rapid intra-chain scission above $\mathrm{T}_{\mathrm{RM}}$.

\section{S6. Interpretation of Arrhenius Data}

Analysis of the initial rates in Figure 4 of the main paper identifies the kinetic transition at $467{ }^{\circ} \mathrm{C}$ observed for both furan product formation as well as cyclodextrin conversion. As shown in Figure S30, the two regimes result in four apparent activation energies when fitted to straight lines above and below $\mathrm{T}_{\mathrm{RM}}$. Cyclodextrin conversion and furan formation below $\mathrm{T}_{\mathrm{RM}}$ both exhibit a slope consistent with an apparent activation energy of $\sim 18 \mathrm{kcal} / \mathrm{mole}$. Above $\mathrm{T}_{\mathrm{RM}}$, furan formation exhibits an apparent activation energy of $11 \mathrm{kcal} / \mathrm{mol}$, while cyclodextrin conversion exhibits an apparent activation energy of $77 \mathrm{kcal} / \mathrm{mol}$.

As stated in the paper, the apparent activation energies of Figure 4 and Figure S30 cannot be readily interpreted without the development of a complex kinetic model. It is possible though misleading ${ }^{39}$ - to simplify the overall chemistry to a single reaction or a few reactions as has been done with numerous lumped kinetic models with data obtained with thermogravimetric analysis. As stated in the paper, the range of these models varies from 10 to $63 \mathrm{kcal} / \mathrm{mol}^{23}$. Interpretation of a complex depolymerization mechanism as a simple reaction (e.g. $A \rightarrow B$ ) oversimplifies the chemistry and leads to misinterpretation of the measured data. For example, the apparent energies of Figure 4 are both very low $\left(E_{a}=11,18 \mathrm{kcal} / \mathrm{mol}\right)$ and very high $\left(E_{a}=77\right.$ $\mathrm{kcal} / \mathrm{mol}$ ). For the temperature range of $400-550{ }^{\circ} \mathrm{C}$, the low activation energies interpreted as simple $(\mathrm{A} \rightarrow \mathrm{B})$ mechanisms would convert almost instantaneously with any reasonable pre- 
exponential factor. Additionally, the high activation energy $\left(\mathrm{E}_{\mathrm{a}}=77 \mathrm{kcal} / \mathrm{mol}\right)$ interpreted as a simple $(A \rightarrow B)$ mechanism would require a pre-exponential factor that is unreasonably high $\left(>10^{24} \mathrm{~s}^{-1}\right)$ for a single reaction to achieve a reasonable rate of conversion which completes in less than a second.

Broadbelt and co-workers ${ }^{23}$ have stated correctly that an activation energy for a simplified rate expression corresponding to a simple lumped model of cellulose conversion (e.g. $\mathrm{A} \rightarrow \mathrm{B}$ ) must be in the range of $\sim 50 \mathrm{kcal} / \mathrm{mol}$ to achieve the appropriate rate of conversion, which they estimated as a cellulose reaction completing with a few seconds at $500{ }^{\circ} \mathrm{C}$. However, it has been demonstrated many times over that polymer decomposition mechanisms requiring numerous steps for either homolytic or heterolytic chemistry result in complex rate expressions comprised of numerous terms. Apparent activation energies in complex rate expressions can result from a combination of initiation, propagation, and termination steps ${ }^{40,41}$, thus resulting in activation energies lower or higher than those of any of the individual steps. Alternatively, the rate expression for of a polymer reaction can reduce to just the activation energy of the initiation step $^{42}$, which can exhibit very high activation energies ${ }^{43,44}$ in the range observed for cyclodextrin/cellulose above $\mathrm{T}_{\mathrm{RM}}$.

Thus, while the range of measured activation energies of Fig. S30 are potentially viable for certain reaction mechanisms and associated models, it is impossible to evaluate the apparent activation energies of Figure 4 at first glance without a complex kinetic model, which will be developed in the coming decade to interpret the new data. Moreover, interpretation of the activation energies for the specific chemistry of chain decomposition is not an integral part of understanding the transition between general chain-end scission versus intra-chain scission, which is the main focus of the paper. 


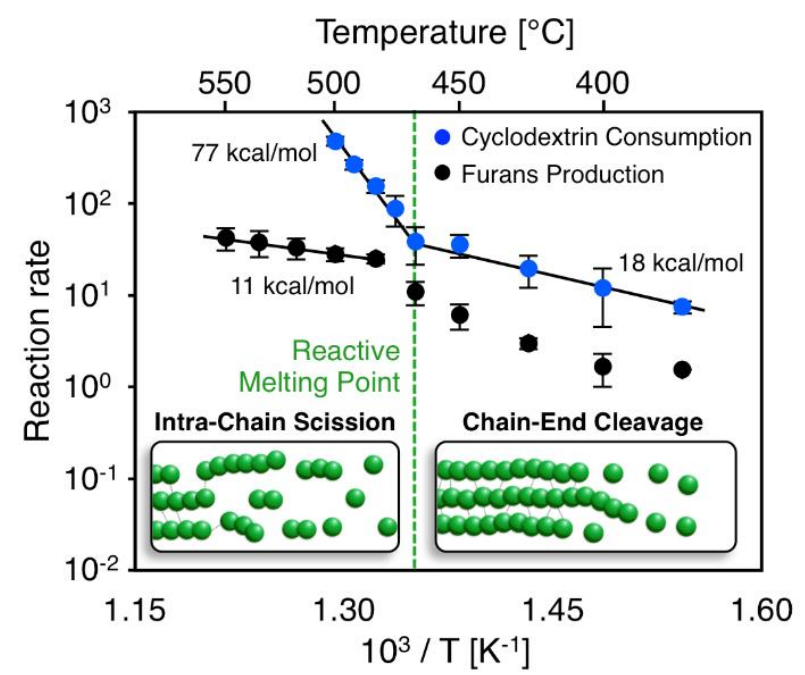

Figure S30. A Different Version of Figure 4 with Measured Apparent Activation Energies.

\section{S7. Cellulose Visualization}

Expanded frames from visualization of reacting cellulose films shown in Figure 1C and 1D of the main paper is presented in this section, as well as supplementary videos available online. Figure S31 shows a diagram of the setup used to collect high speed video frames.

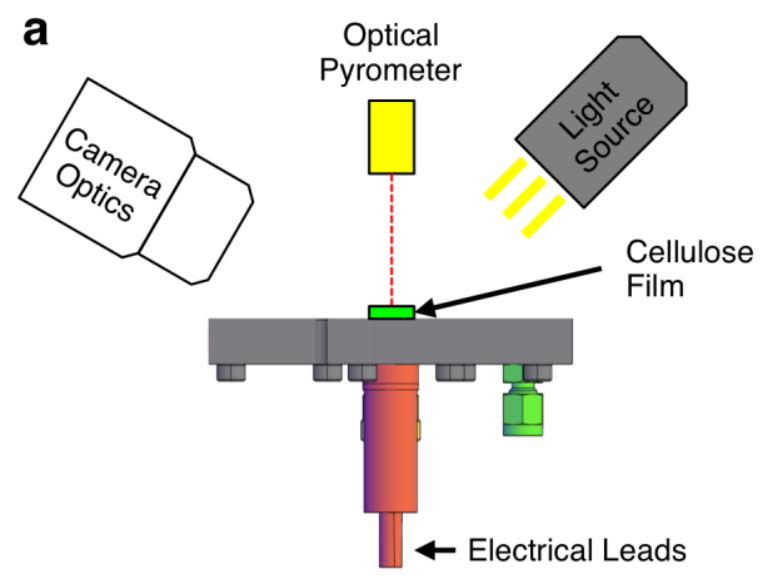

b

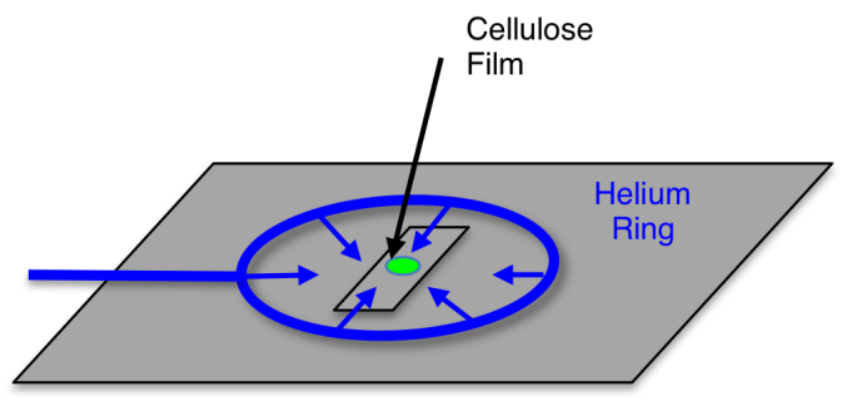

Figure S31. Experimental setup for PHASR Visualization A. A side view of the top section of the PHASR reactor with a high speed camera, optical pyrometer, and light source aimed at the cellulose film. B. A helium diffuser ring around the cellulose film provides an inert environment for visualization of PHASR reactions.

The following section contains expanded frames from the videos shown in Figures 1C and 1D. 


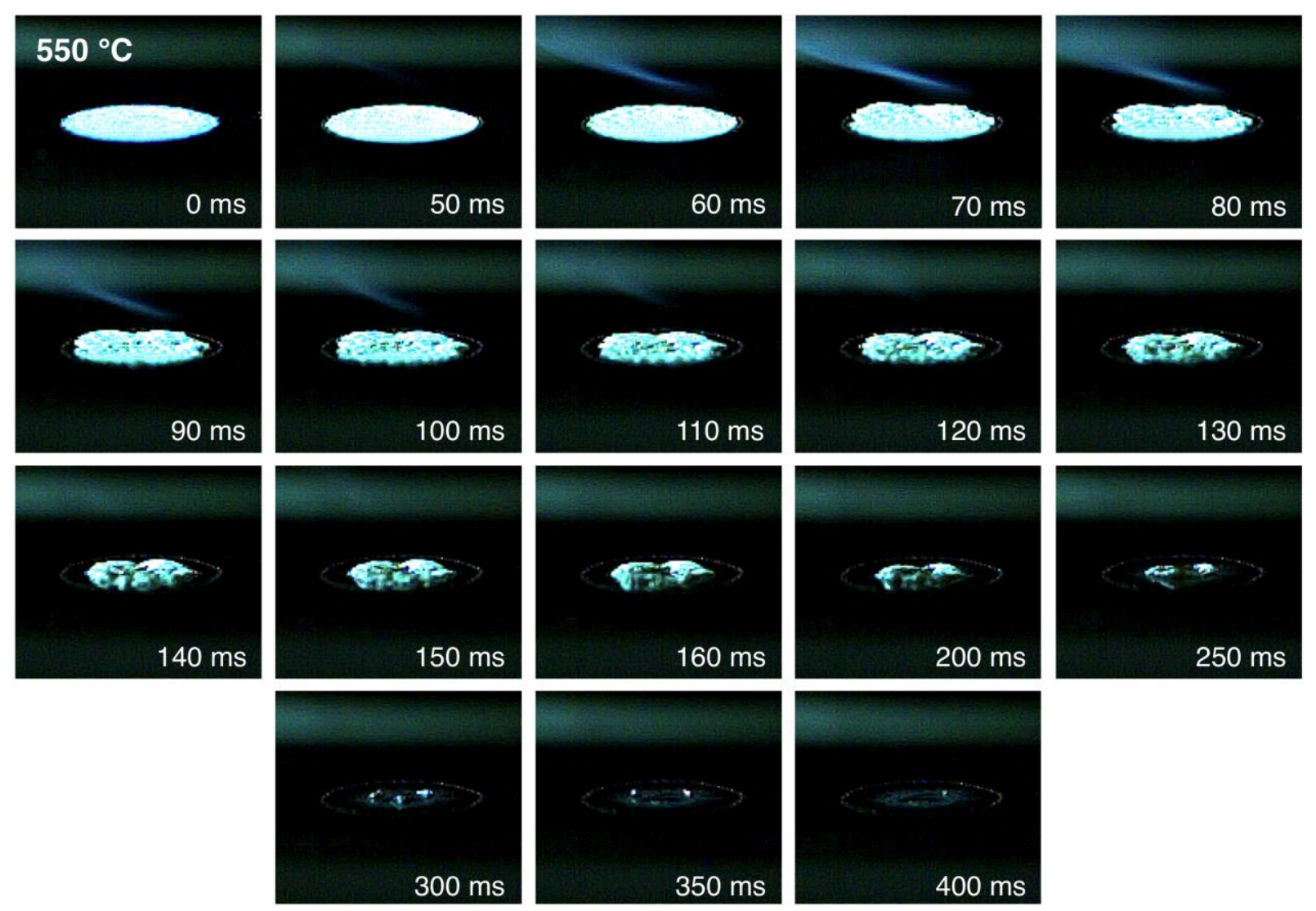

Figure S32. Expanded frames of a reacting cellulose film (20 $\mu \mathrm{m}$ thickness) at $550^{\circ} \mathrm{C}$ as shown in Figure $1 \mathrm{D}$ of the main paper.
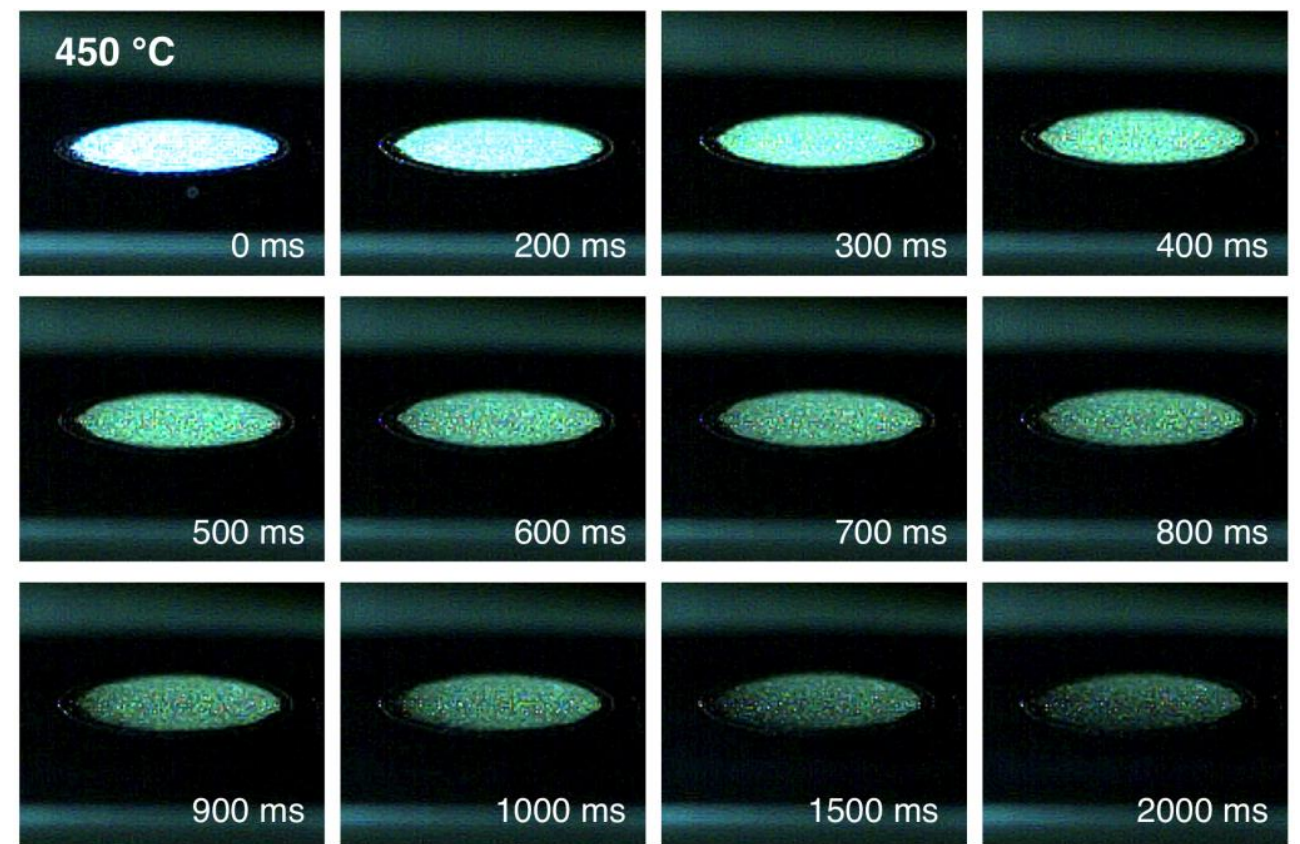

Figure S33. Expanded frames of a reacting cellulose film (20 $\mu \mathrm{m}$ thickness) at $450{ }^{\circ} \mathrm{C}$ as shown in Figure $1 \mathrm{D}$ of the main paper. 


\section{S8. Tabulated PHASR Data}

The following tables contain raw data presented in the main paper, including time resolved data and Arrhenius plots for furans formation and $\alpha$-cyclodextrin consumption. 
Table S6: Time resolved yields of furan products from cellulose at three temperatures. Yield is reported in units of (mol. product i)/(mol. reactant cellulose). ND (not detected) indicates no product was detected at that temperature and pulse time.

\begin{tabular}{cccc} 
Furan \\
\hline Pulse Length [ms] & $400{ }^{\circ} \mathrm{C}$ & $450{ }^{\circ} \mathrm{C}$ & $500{ }^{\circ} \mathrm{C}$ \\
\hline 20 & ND & $1.58 \mathrm{E}-02$ & $2.73 \mathrm{E}-02$ \\
50 & $6.76 \mathrm{E}-03$ & $2.08 \mathrm{E}-02$ & $8.53 \mathrm{E}-02$ \\
75 & $1.27 \mathrm{E}-02$ & $2.22 \mathrm{E}-02$ & $6.23 \mathrm{E}-02$ \\
100 & $9.92 \mathrm{E}-03$ & $7.99 \mathrm{E}-02$ & $7.69 \mathrm{E}-02$ \\
200 & $3.43 \mathrm{E}-02$ & $4.24 \mathrm{E}-02$ & $9.53 \mathrm{E}-02$ \\
300 & $3.61 \mathrm{E}-02$ & $5.50 \mathrm{E}-02$ & $1.06 \mathrm{E}-01$ \\
400 & $4.32 \mathrm{E}-02$ & $6.96 \mathrm{E}-02$ & - \\
500 & $3.94 \mathrm{E}-02$ & $8.90 \mathrm{E}-02$ & $1.20 \mathrm{E}-01$ \\
700 & $5.16 \mathrm{E}-02$ & - & $1.19 \mathrm{E}-01$ \\
1000 & $5.30 \mathrm{E}-02$ & $1.05 \mathrm{E}-01$ & $1.14 \mathrm{E}-01$ \\
1500 & $5.09 \mathrm{E}-02$ & - & - \\
2000 & $1.22 \mathrm{E}-01$ & $2.01 \mathrm{E}-01$ & $4.19 \mathrm{E}-01$ \\
\hline
\end{tabular}

\begin{tabular}{cccc} 
2-Methylfuran & & & \\
\hline Pulse Length $[\mathrm{ms}]$ & $400{ }^{\circ} \mathrm{C}$ & $450{ }^{\circ} \mathrm{C}$ & $500{ }^{\circ} \mathrm{C}$ \\
\hline 20 & $2.61 \mathrm{E}-03$ & $3.91 \mathrm{E}-03$ & $5.27 \mathrm{E}-03$ \\
50 & $3.85 \mathrm{E}-03$ & $6.01 \mathrm{E}-03$ & $1.20 \mathrm{E}-02$ \\
75 & $4.14 \mathrm{E}-03$ & $6.35 \mathrm{E}-03$ & $2.05 \mathrm{E}-02$ \\
100 & $6.29 \mathrm{E}-03$ & $1.48 \mathrm{E}-02$ & $2.77 \mathrm{E}-02$ \\
200 & $9.88 \mathrm{E}-03$ & $2.35 \mathrm{E}-02$ & $3.06 \mathrm{E}-02$ \\
300 & $2.05 \mathrm{E}-02$ & $2.64 \mathrm{E}-02$ & $4.04 \mathrm{E}-02$ \\
400 & $2.92 \mathrm{E}-02$ & $4.30 \mathrm{E}-02$ & - \\
500 & $3.05 \mathrm{E}-02$ & $4.21 \mathrm{E}-02$ & $5.01 \mathrm{E}-02$ \\
700 & $3.67 \mathrm{E}-02$ & - & $5.44 \mathrm{E}-02$ \\
1000 & $4.18 \mathrm{E}-02$ & $4.48 \mathrm{E}-02$ & $5.28 \mathrm{E}-02$ \\
1500 & $5.20 \mathrm{E}-02$ & - & - \\
2000 & $4.56 \mathrm{E}-02$ & $4.80 \mathrm{E}-02$ & $5.20 \mathrm{E}-02$ \\
\hline
\end{tabular}

\begin{tabular}{cccc} 
Dimethylfuran & & & \\
\hline Pulse Length [ms] & $400{ }^{\circ} \mathrm{C}$ & $450{ }^{\circ} \mathrm{C}$ & $500{ }^{\circ} \mathrm{C}$ \\
\hline 20 & ND & $2.33 \mathrm{E}-02$ & $4.03 \mathrm{E}-02$ \\
50 & $6.94 \mathrm{E}-03$ & $2.31 \mathrm{E}-02$ & $7.84 \mathrm{E}-02$ \\
75 & $1.55 \mathrm{E}-02$ & $2.49 \mathrm{E}-02$ & $1.19 \mathrm{E}-01$ \\
100 & $1.03 \mathrm{E}-02$ & $4.67 \mathrm{E}-02$ & $1.61 \mathrm{E}-01$ \\
200 & $1.81 \mathrm{E}-02$ & $7.37 \mathrm{E}-02$ & $1.77 \mathrm{E}-01$ \\
300 & $3.54 \mathrm{E}-02$ & $1.00 \mathrm{E}-01$ & $2.44 \mathrm{E}-01$ \\
400 & $4.11 \mathrm{E}-02$ & $1.45 \mathrm{E}-01$ & - \\
500 & $4.99 \mathrm{E}-02$ & $1.73 \mathrm{E}-01$ & $2.51 \mathrm{E}-01$ \\
700 & $7.54 \mathrm{E}-02$ & - & $2.48 \mathrm{E}-01$ \\
1000 & $6.73 \mathrm{E}-02$ & $1.84 \mathrm{E}-01$ & $2.31 \mathrm{E}-01$ \\
1500 & $5.99 \mathrm{E}-02$ & - & - \\
2000 & $8.59 \mathrm{E}-02$ & $1.66 \mathrm{E}-01$ & $2.98 \mathrm{E}-01$
\end{tabular}

\section{Furfural}

\begin{tabular}{cccc}
\hline Pulse Length $[\mathrm{ms}]$ & $400{ }^{\circ} \mathrm{C}$ & $450{ }^{\circ} \mathrm{C}$ & $500{ }^{\circ} \mathrm{C}$ \\
\hline 20 & $6.02 \mathrm{E}-03$ & $4.34 \mathrm{E}-02$ & $1.01 \mathrm{E}-01$ \\
50 & $1.18 \mathrm{E}-02$ & $9.23 \mathrm{E}-02$ & $2.61 \mathrm{E}-01$ \\
75 & $1.94 \mathrm{E}-02$ & $1.35 \mathrm{E}-01$ & $3.89 \mathrm{E}-01$ \\
100 & $3.67 \mathrm{E}-02$ & $1.42 \mathrm{E}-01$ & $5.13 \mathrm{E}-01$ \\
200 & $6.54 \mathrm{E}-02$ & $3.56 \mathrm{E}-01$ & $6.56 \mathrm{E}-01$ \\
300 & $1.59 \mathrm{E}-01$ & $4.74 \mathrm{E}-01$ & $8.23 \mathrm{E}-01$ \\
400 & $1.88 \mathrm{E}-01$ & $5.97 \mathrm{E}-01$ & - \\
500 & $2.23 \mathrm{E}-01$ & $6.49 \mathrm{E}-01$ & $8.96 \mathrm{E}-01$ \\
700 & $2.52 \mathrm{E}-01$ & $6.58 \mathrm{E}-01$ & $8.88 \mathrm{E}-01$ \\
1000 & $2.89 \mathrm{E}-01$ & $3.50 \mathrm{E}-01$ & $8.81 \mathrm{E}-01$ \\
1500 & $3.02 \mathrm{E}-01$ & - & - \\
2000 & $3.71 \mathrm{E}-01$ & $6.56 \mathrm{E}-01$ & $1.00 \mathrm{E}+00$
\end{tabular}

2-Furanmethanol

\begin{tabular}{cccc}
\hline Pulse Length $[\mathrm{ms}]$ & $400{ }^{\circ} \mathrm{C}$ & $450{ }^{\circ} \mathrm{C}$ & $500{ }^{\circ} \mathrm{C}$ \\
\hline 20 & $5.80 \mathrm{E}-03$ & $6.33 \mathrm{E}-02$ & $1.23 \mathrm{E}-01$ \\
50 & $1.40 \mathrm{E}-02$ & $7.54 \mathrm{E}-02$ & $2.28 \mathrm{E}-01$ \\
75 & $2.83 \mathrm{E}-02$ & $6.33 \mathrm{E}-02$ & $2.94 \mathrm{E}-01$ \\
100 & $2.74 \mathrm{E}-02$ & $1.68 \mathrm{E}-01$ & $3.67 \mathrm{E}-01$ \\
200 & $8.63 \mathrm{E}-02$ & $2.84 \mathrm{E}-01$ & $3.92 \mathrm{E}-01$ \\
300 & $2.11 \mathrm{E}-01$ & $3.71 \mathrm{E}-01$ & $4.41 \mathrm{E}-01$ \\
400 & $2.64 \mathrm{E}-01$ & $4.79 \mathrm{E}-01$ & - \\
500 & $2.73 \mathrm{E}-01$ & $5.63 \mathrm{E}-01$ & $4.82 \mathrm{E}-01$ \\
700 & $3.53 \mathrm{E}-01$ & - & $4.57 \mathrm{E}-01$ \\
1000 & $3.85 \mathrm{E}-01$ & $5.21 \mathrm{E}-01$ & $5.20 \mathrm{E}-01$ \\
1500 & $3.04 \mathrm{E}-01$ & - & - \\
2000 & $3.92 \mathrm{E}-01$ & $5.48 \mathrm{E}-01$ & $7.65 \mathrm{E}-01$
\end{tabular}

2(5H)-Furanone

\begin{tabular}{cccc}
\hline Pulse Length [ms] & $400{ }^{\circ} \mathrm{C}$ & $450{ }^{\circ} \mathrm{C}$ & $500{ }^{\circ} \mathrm{C}$ \\
\hline 20 & ND & $5.15 \mathrm{E}-02$ & $7.19 \mathrm{E}-02$ \\
50 & $2.76 \mathrm{E}-02$ & $6.92 \mathrm{E}-02$ & $3.13 \mathrm{E}-01$ \\
75 & $3.82 \mathrm{E}-02$ & $8.57 \mathrm{E}-02$ & $5.70 \mathrm{E}-01$ \\
100 & $3.69 \mathrm{E}-02$ & $2.02 \mathrm{E}-01$ & $7.51 \mathrm{E}-01$ \\
200 & $5.97 \mathrm{E}-02$ & $3.46 \mathrm{E}-01$ & $7.97 \mathrm{E}-01$ \\
300 & $1.68 \mathrm{E}-01$ & $4.18 \mathrm{E}-01$ & $1.11 \mathrm{E}+00$ \\
400 & $1.95 \mathrm{E}-01$ & $6.80 \mathrm{E}-01$ & - \\
500 & $2.73 \mathrm{E}-01$ & $8.45 \mathrm{E}-01$ & $1.14 \mathrm{E}+00$ \\
700 & $4.01 \mathrm{E}-01$ & - & $1.13 \mathrm{E}+00$ \\
1000 & $3.51 \mathrm{E}-01$ & $8.34 \mathrm{E}-01$ & $1.04 \mathrm{E}+00$ \\
1500 & $1.24 \mathrm{E}-01$ & - & - \\
2000 & $4.01 \mathrm{E}-01$ & $7.27 \mathrm{E}-01$ & $1.18 \mathrm{E}+00$ \\
\hline & & & \\
HMF & & & \\
\hline Pulse Length [ms] & $400{ }^{\circ} \mathrm{C}$ & $450{ }^{\circ} \mathrm{C}$ & $500{ }^{\circ} \mathrm{C}$ \\
\hline 20 & $1.46 \mathrm{E}-02$ & $3.78 \mathrm{E}-02$ & $3.03 \mathrm{E}-02$ \\
50 & $2.79 \mathrm{E}-02$ & $3.30 \mathrm{E}-02$ & $2.77 \mathrm{E}-01$ \\
75 & $2.68 \mathrm{E}-02$ & $3.51 \mathrm{E}-02$ & $2.33 \mathrm{E}-01$ \\
100 & $2.64 \mathrm{E}-02$ & $4.59 \mathrm{E}-02$ & $3.34 \mathrm{E}-01$ \\
200 & $3.48 \mathrm{E}-02$ & $7.27 \mathrm{E}-02$ & $3.59 \mathrm{E}-01$ \\
300 & $4.77 \mathrm{E}-02$ & $8.41 \mathrm{E}-02$ & $2.60 \mathrm{E}-01$ \\
400 & $4.24 \mathrm{E}-02$ & $1.08 \mathrm{E}-01$ & - \\
500 & $6.09 \mathrm{E}-02$ & $1.13 \mathrm{E}-01$ & $4.59 \mathrm{E}-01$ \\
700 & $1.05 \mathrm{E}-01$ & - & - \\
1000 & $4.48 \mathrm{E}-02$ & $1.45 \mathrm{E}-01$ & $5.60 \mathrm{E}-01$ \\
1500 & $5.78 \mathrm{E}-02$ & - & - \\
2000 & $1.08 \mathrm{E}-01$ & $2.91 \mathrm{E}-01$ & $5.62 \mathrm{E}-01$ \\
\hline & & &
\end{tabular}

\begin{tabular}{cccc} 
5-Methylfurfural & & & \\
\hline Pulse Length [ms] & $400{ }^{\circ} \mathrm{C}$ & $450{ }^{\circ} \mathrm{C}$ & $500{ }^{\circ} \mathrm{C}$ \\
\hline 20 & $4.23 \mathrm{E}-03$ & $1.97 \mathrm{E}-02$ & $3.58 \mathrm{E}-02$ \\
50 & $4.08 \mathrm{E}-03$ & $3.05 \mathrm{E}-02$ & $1.07 \mathrm{E}-01$ \\
75 & $3.82 \mathrm{E}-02$ & $3.57 \mathrm{E}-02$ & $1.32 \mathrm{E}-01$ \\
100 & $1.28 \mathrm{E}-02$ & $6.20 \mathrm{E}-02$ & $1.52 \mathrm{E}-01$ \\
200 & $2.24 \mathrm{E}-02$ & $8.31 \mathrm{E}-02$ & $1.52 \mathrm{E}-01$ \\
300 & $2.68 \mathrm{E}-02$ & $1.12 \mathrm{E}-01$ & $2.07 \mathrm{E}-01$ \\
400 & $5.55 \mathrm{E}-02$ & $1.43 \mathrm{E}-01$ & - \\
500 & $4.48 \mathrm{E}-02$ & $1.67 \mathrm{E}-01$ & $2.25 \mathrm{E}-01$ \\
700 & $4.91 \mathrm{E}-02$ & - & $2.22 \mathrm{E}-01$ \\
1000 & $7.73 \mathrm{E}-02$ & $2.24 \mathrm{E}-11$ & $2.18 \mathrm{E}-01$ \\
1500 & $6.53 \mathrm{E}-02$ & - & - \\
2000 & $7.95 \mathrm{E}-02$ & $1.56 \mathrm{E}-01$ & $2.62 \mathrm{E}-01$ \\
\hline & & & \\
Total Furans & & & \\
\hline Pulse Length [ms] & $400{ }^{\circ} \mathrm{C}$ & $450{ }^{\circ} \mathrm{C}$ & $500{ }^{\circ} \mathrm{C}$ \\
\hline 20 & $3.33 \mathrm{E}-02$ & $2.59 \mathrm{E}-01$ & $4.35 \mathrm{E}-01$ \\
50 & $1.03 \mathrm{E}-01$ & $3.50 \mathrm{E}-01$ & $1.36 \mathrm{E}+00$ \\
75 & $1.83 \mathrm{E}-01$ & $4.08 \mathrm{E}-01$ & $1.82 \mathrm{E}+00$ \\
100 & $1.67 \mathrm{E}-01$ & $7.61 \mathrm{E}-01$ & $2.38 \mathrm{E}+00$ \\
200 & $3.31 \mathrm{E}-01$ & $1.28 \mathrm{E}+00$ & $2.66 \mathrm{E}+00$ \\
300 & $7.04 \mathrm{E}-01$ & $1.64 \mathrm{E}+00$ & $3.23 \mathrm{E}+00$ \\
400 & $8.59 \mathrm{E}-01$ & $2.27 \mathrm{E}+00$ & - \\
500 & $9.95 \mathrm{E}-01$ & $2.64 \mathrm{E}+00$ & $3.62 \mathrm{E}+00$ \\
700 & $1.32 \mathrm{E}+00$ & - & - \\
1000 & $1.31 \mathrm{E}+00$ & $2.18 \mathrm{E}+00$ & $3.62 \mathrm{E}+00$ \\
2000 & $1.60 \mathrm{E}+00$ & $2.79 \mathrm{E}+00$ & $4.54 \mathrm{E}+00$ \\
\hline & & &
\end{tabular}


Table S7: Arrhenius data for production of furans from cellulose. Reaction rates are reported as (mol. product i) $/($ mol. cellulose reactant $) *($ second $)$.

\begin{tabular}{cccc} 
Furan & & & \\
\hline $\mathrm{T}(\mathrm{C})$ & Pulse Length [ms] & Rate & Error \\
\hline 375 & 500 & 0.09 & - \\
400 & 200 & 0.17 & 0.015 \\
425 & 150 & 0.24 & 0.014 \\
450 & 100 & 0.58 & 0.042 \\
467 & 83 & 0.79 & 0.015 \\
483 & 67 & 1.33 & 0.002 \\
500 & 50 & 1.73 & 0.007 \\
517 & 20 & 2.46 & 0.044 \\
534 & 20 & 2.89 & 0.233 \\
550 & 20 & 3.65 & 0.111 \\
\hline
\end{tabular}

2-Methylfuran

\begin{tabular}{cccc}
\hline $\mathrm{T}(\mathrm{C})$ & Pulse Length & Rate & Error \\
\hline 375 & 500 & 0.03 & - \\
400 & 200 & 0.05 & 0.002 \\
425 & 150 & 0.06 & 0.002 \\
450 & 100 & 0.10 & 0.009 \\
467 & 83 & 0.11 & 0.002 \\
483 & 67 & 0.18 & 0.002 \\
500 & 50 & 0.24 & 0.001 \\
517 & 20 & 0.26 & 0.016 \\
534 & 20 & 0.32 & 0.014 \\
550 & 20 & 0.42 & 0.014
\end{tabular}

\begin{tabular}{cccc}
\multicolumn{3}{l}{ Dimethylfuran } \\
\hline $\mathrm{T}(\mathrm{C})$ & Pulse Length [ms] & Rate & Error \\
\hline 375 & 500 & 0.08 & - \\
400 & 200 & 0.06 & 0.008 \\
425 & 150 & 0.13 & 0.006 \\
450 & 100 & 0.25 & 0.023 \\
467 & 83 & 0.35 & 0.023 \\
483 & 67 & 1.00 & 0.042 \\
500 & 50 & 1.07 & 0.039 \\
517 & 20 & 1.72 & 0.069 \\
534 & 20 & 1.90 & 0.254 \\
550 & 20 & 2.39 & 0.248 \\
\hline
\end{tabular}

\section{Furfural}

\begin{tabular}{cccc} 
Furfural & & & \\
\hline $\mathrm{T}(\mathrm{C})$ & Pulse Length & Rate & Error \\
\hline 375 & 500 & 0.36 & - \\
400 & 200 & 0.33 & 0.046 \\
425 & 150 & 0.55 & 0.009 \\
450 & 100 & 1.17 & 0.035 \\
467 & 83 & 2.27 & 0.101 \\
483 & 67 & 3.88 & 0.093 \\
500 & 50 & 5.49 & 0.216 \\
517 & 20 & 6.99 & 0.228 \\
534 & 20 & 7.36 & 0.480 \\
550 & 20 & 8.50 & 0.197 \\
\hline
\end{tabular}

\begin{tabular}{cccc}
\multicolumn{2}{l}{ 2-Furanmethanol } & & \\
\hline $\mathrm{T}(\mathrm{C})$ & Pulse Length [ms] & Rate & Error \\
\hline 375 & 500 & 0.39 & - \\
400 & 200 & 0.43 & 0.033 \\
425 & 150 & 0.59 & 0.006 \\
450 & 100 & 1.37 & 0.072 \\
467 & 83 & 2.64 & 0.153 \\
483 & 67 & 4.66 & 0.140 \\
500 & 50 & 4.68 & 0.173 \\
517 & 20 & 5.31 & 0.217 \\
534 & 20 & 6.39 & 0.657 \\
550 & 20 & 7.23 & 0.665 \\
\hline
\end{tabular}

\begin{tabular}{cccc} 
2(5H)-Furanone & & \\
\hline $\mathrm{T}(\mathrm{C})$ & Pulse Length & Rate & Error \\
\hline 375 & 500 & 0.39 & - \\
400 & 200 & 0.30 & 0.011 \\
425 & 150 & 0.58 & 0.034 \\
450 & 100 & 1.33 & 0.140 \\
467 & 83 & 1.91 & 0.130 \\
483 & 67 & 5.18 & 0.147 \\
500 & 50 & 6.23 & 0.114 \\
517 & 20 & 6.75 & 0.355 \\
534 & 20 & 5.56 & 0.266 \\
550 & 20 & 7.76 & 0.635 \\
\hline
\end{tabular}

\begin{tabular}{cccc}
\multicolumn{4}{l}{ 5-Methylfurfural } \\
\hline $\mathrm{T}(\mathrm{C})$ & Pulse Length [ms] & Rate & Error \\
\hline 375 & 500 & 0.08 & - \\
400 & 200 & 0.11 & 0.002 \\
425 & 150 & 0.32 & 0.001 \\
450 & 100 & 0.60 & 0.014 \\
467 & 83 & 0.98 & 0.040 \\
483 & 67 & 2.01 & 0.011 \\
500 & 50 & 2.06 & 0.046 \\
517 & 20 & 3.70 & 0.184 \\
534 & 20 & 3.72 & 0.244 \\
550 & 20 & 4.43 & 0.067 \\
\hline
\end{tabular}

\begin{tabular}{cccc} 
HMF & & & \\
\hline $\mathrm{T}(\mathrm{C})$ & Pulse Length $[\mathrm{ms}]$ & Rate & Error \\
\hline 375 & & 0.12 & - \\
400 & 200 & 0.17 & 0.015 \\
425 & & 0.47 & 0.009 \\
450 & 100 & 0.57 & 0.040 \\
467 & 83 & 1.66 & 0.153 \\
483 & 67 & 6.45 & 0.116 \\
500 & 50 & 6.17 & 0.319 \\
517 & 20 & 5.31 & 0.611 \\
534 & 20 & 8.97 & 0.215 \\
550 & 20 & 7.09 & 0.428 \\
\hline
\end{tabular}

\begin{tabular}{cccc}
\multicolumn{4}{l}{ Total Furans } \\
\hline $\mathrm{T}(\mathrm{C})$ & Pulse Length $[\mathrm{ms}]$ & Rate & Error \\
\hline 375 & 500 & 1.53 & - \\
400 & 200 & 1.65 & 0.657 \\
425 & 150 & 3.00 & 0.408 \\
450 & 100 & 6.09 & 1.871 \\
467 & 83 & 10.85 & 3.088 \\
483 & 67 & 25.09 & 2.767 \\
500 & 50 & 28.10 & 4.580 \\
517 & 20 & 33.20 & 8.614 \\
534 & 20 & 37.87 & 11.804 \\
550 & 20 & 42.44 & 11.821 \\
\hline
\end{tabular}


Table S8: Arrhenius data for production of furans from cellulose. Reaction rates are reported as (mol. $\alpha$ cyclodextrin consumed $) /($ mol. $\alpha$-cyclodextrin reactant $) *($ second $)$.

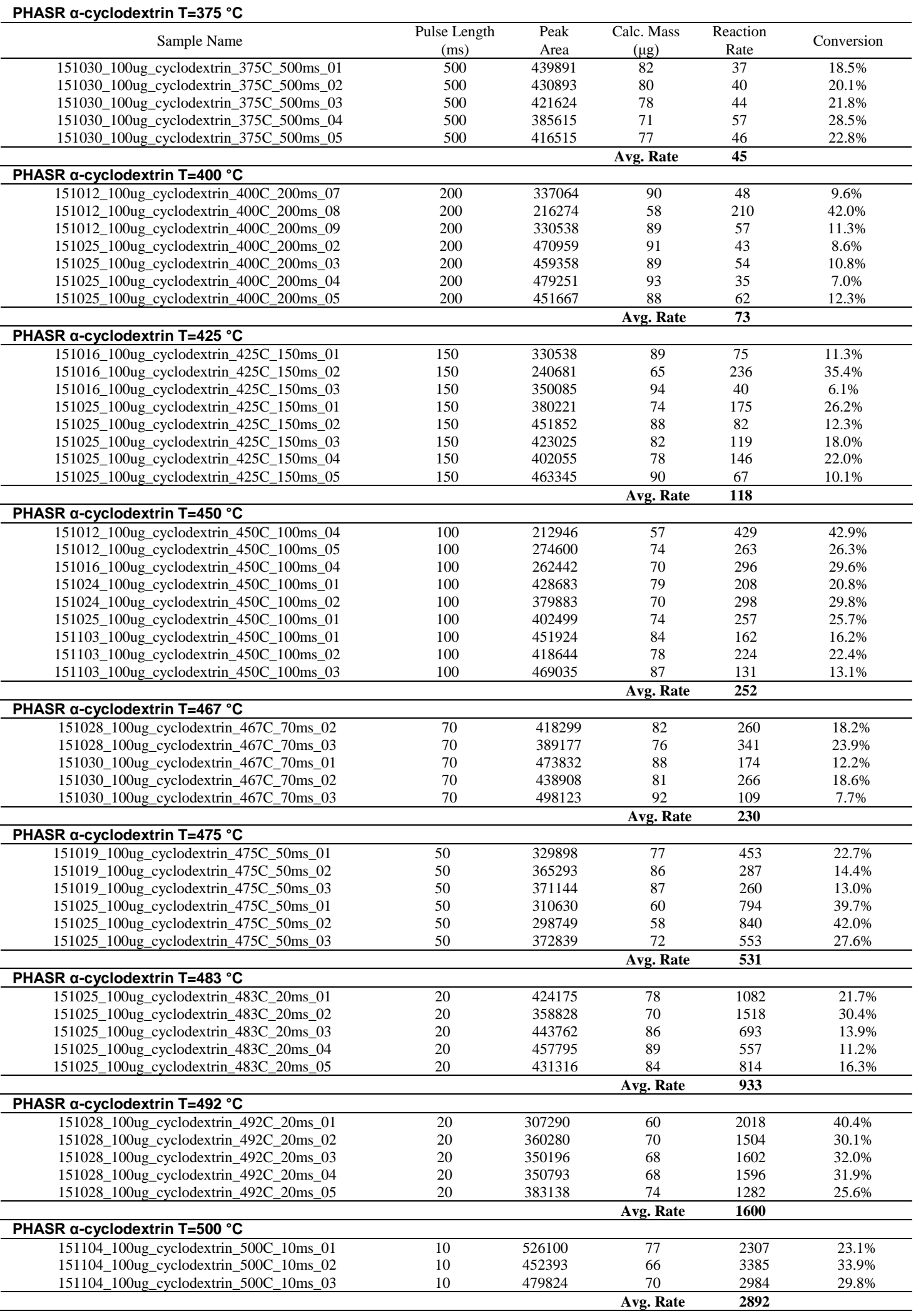




\section{Supplementary Information - References}

7. Mettler, M. S., Paulsen, A. D., Vlachos, D. G. \& Dauenhauer, P. J. Pyrolytic conversion of cellulose to fuels: levoglucosan deoxygenation via elimination and cyclization within molten biomass. Energy \& Environmental Science 5, 7864-7868, doi:10.1039/C2EE21305B (2012).

11. Bradbury, A. G. W., Sakai, Y. \& Shafizadeh, F. A kinetic model for pyrolysis of cellulose. Journal of Applied Polymer Science 23, 3271-3280, doi:10.1002/app.1979.070231112 (1979).

23. Burnham, A. K., Zhou, X. \& Broadbelt, L. J. Critical Review of the Global Chemical Kinetics of Cellulose Thermal Decomposition. Energy \& Fuels 29, 2906-2918, doi:10.1021/acs.energyfuels.5b00350 (2015).

27. Mayes, H. B., Nolte, M. W., Beckham, G. T., Shanks, B. H. \& Broadbelt, L. J. The Alpha-Bet(a) of Glucose Pyrolysis: Computational and Experimental Investigations of 5Hydroxymethylfurfural and Levoglucosan Formation Reveal Implications for Cellulose Pyrolysis. ACS Sustainable Chemistry \& Engineering 2, 1461-1473, doi:10.1021/sc500113m (2014).

39. Properties and Behavior of Polymers (Wiley, New York, 2011)

40. Bamford, C.H., Tipper, C.F.H. Comprehensive Chemical Kinetics, Vol. 14: Degradation of Polymers (Elsevier, Amsterdam, 1975)

41. Green, N.J.B. Chemical Kinetics: Kinetics of Multistep Reactions $\mathbf{4 0}$ (Elsevier, Amsterdam, 2004)

42. Emmett, P.H. Catalysis, Vol. VI: Alkylation, Isomerization, Polymerization, Cracking and Hydroreforming (Reinhold, New York, 1953)

43. Wall, L.A., Florin, R.E. Effect of structure on the thermal decomposition of polymers. J. Res. Natnl. Bur. Stand. 60 (1958).

44. Wall, L.A., Straus, S. Pyrolysis of Fluorocarbon Polymers. J. Res. Natnl. Bur. Stand. 65, 227, (1961). 